\title{
Hydrocarbon pollutants shape bacterial community assembly of harbor sediments
}

$\underline{\text { Marta Barbato }^{1 \S} \text {, Francesca Mapelli }}{ }^{1 \S}$, Mirko Magagnini ${ }^{2}$, Bessem Chouaia ${ }^{1, a}$, Monica Armeni ${ }^{2}$, Ramona Marasco $^{3}$, Elena Crotti ${ }^{1}$, Daniele Daffonchio ${ }^{1,3}$, Sara Borin $^{1 *}$

${ }^{1}$ Department of Food, Environmental and Nutritional Sciences (DeFENS), University of Milan, Milan, Italy

${ }^{2}$ EcoTechSystems Ltd., Ancona, Italy.

${ }^{3}$ Biological and Environmental Sciences and Engineering Division (BESE). King Abdullah University of Science and Technology (KAUST), Thuwal, 23955-6900, Kingdom of Saudi Arabia

a Actual address: Department of Entomology, 5142 Comstock Hall, Cornell University, Ithaca, NY, 14853, United States of America

${ }^{\S}$ These authors equally contributed to this work

* Corresponding author (email: sara.borin@unimi.it)

\begin{abstract}
Petroleum pollution results in co-contamination by different classes of molecules, entailing the occurrence of marine sediments difficult to remediate, as in the case of the Ancona harbor (Mediterranean Sea, Italy). Autochthonous bioaugmentation (ABA), by exploiting the indigenous microbes of the environment to be treated, could represent a successful bioremediation strategy. In this perspective we aimed to i) identify the main drivers of the bacterial communities' richness in the sediments, ii) establish enrichment cultures with different hydrocarbon pollutants evaluating their effects on the bacterial communities' composition, and iii) obtain a collection of hydrocarbon degrading bacteria potentially exploitable in ABA. The correlation between the selection of different specialized bacterial populations and the type of pollutants was demonstrated by culture-independent analyses, and by establishing a collection of bacteria with different hydrocarbon degradation traits. Our observations indicate that pollution dictates the diversity of sediment bacterial communities and shapes the ABA potential in harbor sediments.
\end{abstract}




\section{KEYWORDS}

Oil contamination; autochthonous bioaugmentation; pyrosequencing; bacterial community; Alcanivorax

\section{INTRODUCTION}

The Mediterranean Sea is one of the most congested basins in terms of oil tanker traffic, hosting about $20 \%$ of the global traffic. Furthermore the coastlines are densely inhabited and, especially in the northern side, highly industrialized. As a consequence, Mediterranean coasts and harbors, especially the industrial ones, are constantly exposed to crude oil hydrocarbons (HC) deriving mainly from oil tankers and wastes of refineries, chemical industries and oil pipelines (Daffonchio et al., 2013, 2012). The thousands of different oil molecules have a wide range of physico-chemical properties and toxicity. The individual molecules within the four main groups of oil $\mathrm{HC}$, saturated $\mathrm{HC}$, aromatic $\mathrm{HC}$, resins and asphaltenes, are also classified according to their molecular weight into light fractions (low molecular weight) and heavy fractions (high molecular weight). The latter includes the most recalcitrant compounds to degradation that tend to accumulate in the sediments of harbors and coastal areas nearby oil-related facilities.

The Ancona harbor (Italy) is located in the Adriatic Sea and is one of the largest Mediterranean commercial harbors, with intense ferry and merchant fluxes, and it is surrounded by shipyards and important industrial plants. High concentration of pollutant chemicals, including aliphatic HC, polycyclic aromatic HC and naphthalene have been measured in its sediments, along with high concentration of different heavy metals like Cu, Mn, Ni and Zn (Dell'Anno et al., 2009; Mei and Danovaro, 2004; Mirto and Danovaro, 2004)

Bioaugmentation is the addition of degrading bacteria to a polluted environment and it is recognized as a potential strategy for supporting the clean-up of polluted sediments (Head et al., 2006). We have recently shown that the origin of the added microorganisms is essential to predict the success of a sediment treatment through bioaugmentation and that allochthonous microorganisms present several limitations due to the adaptation to the local environmental conditions (Fodelianakis et al., 2015). In this perspective, a new approach for bioaugmentation, called autochthonous bioaugmentation (ABA), has been proposed (Hosokawa et al., 2009) and recognized as the best strategy for remediate marine oil polluted samples (Nikolopoulou et al., 2013). ABA is a site-tailored strategy based on the use of autochthonous microbial populations, 
previously enriched under laboratory conditions and re-inoculated in the polluted site to be treated, taking advantage of their natural ability to cope with the unique environmental setting where they come from. To set-up successful ABA strategy, it is pivotal to gain knowledge of the indigenous microbial populations, of the occurring environmental parameters and their influence on survival and degradation rate of the selected microorganisms.

The present study aimed to assess i) the driving factors shaping the bacterial communities inhabiting the Ancona harbor's sediments through culture-dependent and independent approaches and ii) the effect of different HC pollutants on the bacterial community richness and diversity.

\section{MATERIALS and METHODS}

\section{1 - Sites description and sampling and sediment physico-chemical characterization}

Sediment samples were collected from ten polluted stations in the harbor (codes: U1 - U10) and five control pristine stations (codes: $\mathrm{C} 1$ - C5) $3.5 \mathrm{~km}$ far away from the harbor, along the dominant NW/SE current (Table 1, Figure 1a). Sampling depths ranged from $2.5 \mathrm{~m}$ in the harbor area to $13 \mathrm{~m}$ in the control stations. For each sample, $\mathrm{pH}$ and redox potential were measured. Samples for granulometric analyses (percentages of gravel, sand and clay in the sediment), humidity and specific weight were transferred into plastic containers and stored at $+4^{\circ} \mathrm{C}$. For the analyses of trace metals, $\mathrm{HC}$ and total polycyclic aromatic hydrocarbons (PAHs), samples were transferred into inert HDPE containers and stored at $-18^{\circ} \mathrm{C}$ until laboratory analyses. Samples for the determination of total organic carbon (TOC) and molecular ecology analyses were transferred, respectively, into Petri dishes and sterile plastic containers, and stored at $-20^{\circ} \mathrm{C}$. For the determination of total bacteria, sediment slurries were prepared using sterile buffered formaldehyde (4\% final concentration), while for bacteria isolation sediment sub-samples were collected using a sterile spoon and stored at $+4^{\circ} \mathrm{C}$. TOC was determined by weight loss on combustion technique after removal of carbonate with dilute (IN) $\mathrm{HCl}$. A portion of sediments was weighed into a porcelain crucible and ignited in a muffle furnace at $550^{\circ} \mathrm{C}$ for two hours. The crucible was cooled in a desiccator, re-weighed and the TOC was calculated as the weight loss in percentage (Gaudette E., Flight R., Toner L., 1974). The presence and abundance of different HC - 
C>12 and PAHs- was estimated by chromatographic techniques. The HC concentration was analyzed by Agilent 7890 -USA. A HP-5 capillary chromatographic column (30 m x $0.32 \mathrm{~mm}$ I.D.) and a capillary column (30 m x $0.25 \mathrm{~mm}$ I.D.) were used for GC-FID and GC-MS analyses, respectively. Nitrogen was the carrier gas with $3 \mathrm{ml} / \mathrm{min}$. Injector and detector temperatures were maintained at $300{ }^{\circ} \mathrm{C}$ and $320{ }^{\circ} \mathrm{C}$, respectively. The identification of n-paraffin peaks was established using a reference mixture of n-paraffin of known composition.

To determine the total content of heavy metals $(\mathrm{Cu}, \mathrm{Zn}, \mathrm{Cr}, \mathrm{Ni}, \mathrm{Cd}, \mathrm{Pb}, \mathrm{Hg}, \mathrm{V}$ and $\mathrm{As})$ in sediments, samples (0.1 g) were digested with $\mathrm{HNO}_{3} / \mathrm{HClO}_{4}(4: 1, \mathrm{v} / \mathrm{v})$ in a microwave oven (CEM, MARS5). After digestion, the volume of each sample was adjusted to $20 \mathrm{~mL}$ using deionized water. Heavy metals and As content was determined by Inductively Coupled Plasma-Mass Spectrometry (ICP-MS, Agilent Technologies, Santa Clara, CA, USA). Standards of heavy metals and of As for concentrations ranging from 0 to $1 \mathrm{mg} / \mathrm{L}$ were prepared from multi-element calibration standard-2A solution (Agilent Technologies) and from sodium arsenite solution $\left(\mathrm{NaAsO}_{2}\right.$ ) (Sigma-Aldrich, St Louis, MO, USA) respectively. For all the measures by ICPMS an aliquot of a $2 \mathrm{mg} / \mathrm{L}$ of an internal standard solution (45Sc, 89Y, 159Tb, Agilent Technologies) was added both to samples and a calibration curve to give a final concentration of $20 \mu \mathrm{g} / \mathrm{L}$. The instrument was tuned daily with a multi-element tuning solution for optimized signal-to-noise ratio.

\section{2 - Total prokaryote and hydrocarbonoclastic bacteria abundance}

Total prokaryotic abundance was determined on sediment collected in the surface layer $(0-1 \mathrm{~cm})$. The samples were suspended in pyrophosphate solution (final concentration $5 \mathrm{mM}$ ) and sonicated (60 W, one minute for three consecutive times, with 30 -seconds intervals). The supernatant was then sub-sampled and filtered into sterile $0.2 \mu \mathrm{m}$ pore-size filters. Filters were then stained with SYBR Green I and cells counted by means of Epifluorescence Microscope (EFM) at 1000X magnification.

The number of HC-degrading bacteria in the U5 and U7 sites was evaluated through the Most Probable Number (MPN) method, modifying the previously described method (Cappello et al., 2006). Serial dilutions of the sediments were performed and inoculated 1:10 in triplicates in ONR7a mineral medium (Dyksterhouse 
et al., 1995) added with crude oil (1\% v/v) as unique carbon source and cycloheximide $(0.01 \% \mathrm{w} / \mathrm{v})$ to inhibit eukaryotic growth. Bacterial growth was evaluated after 28 days static incubation at $25^{\circ} \mathrm{C}$.

\section{3 - Bacterial ARISA fingerprinting and community 16S rRNA gene profiling and sequencing}

Total DNA was extracted from $0.5 \mathrm{~g}$ of sediment using the "Power Soil" kit (MoBio Laboratories Inc., Carlsbad, CA, USA) following the manufacturer's instructions. DNA was quantified using a NanoDrop 1000 spectrophotometer (Thermo Scientific, Waltham, MA, USA).

ARISA-PCR was conducted on 20 ng of DNA template on each sample by using the primer set ITSF, 5'GTC GTA ACA AGG TAG GCC GTA-3’ and ITSReub, 5’-GCC AAG GCA TCC ACC 3', as previously described (Cardinale et al., 2004). ARISA fragments were separated by using the ABI3730XL genetic analyzer applying the internal standard 1200-LIZ. The output peak matrix was transferred to Microsoft Excel for the following analysis. Peaks showing height value $<50$ were removed from the output peak matrix before statistical analyses. Each polymorphic ARISA peak is defined as a different OTU. Richness was defined as the number of OTUs present in each sample.

Barcoded pyrosequencing assays on the $16 \mathrm{~S}$ rRNA gene were carried out using bacterial universal primers (27 F mod 5' - AGRGTTTGATCMTGGCTCAG - 3'; 519 R mod bio 5' - GTNTTACNGCGGCKGCTG 3') targeting the variable regions of $16 \mathrm{~S}$ rRNA V1-V3 and amplifying a fragment of approximately $400 \mathrm{bp}$. The amplified 16S rRNA regions contain enough nucleotide variability to be useful in identification of bacterial species (Chakravorty et al., 2007; Van de Peer et al., 1996). PCR reactions and next generation 454 pyrosequencing were performed by the company MR DNA (Shallowater, TX - U.S.) as previously described (Bargiela et al., 2015a). A total of 66365 raw, barcoded amplicons of the V1-V3 region of the 16S rRNA gene, were obtained. The reads were trimmed to remove pyrosequencing adaptors, low quality base calls (<30 Phred score) and size-selected (between 350 and 500 bp) using the QIIME (Caporaso et al., 2010) pipeline filtering scripts. High quality sequence reads that were not flagged as chimeras after screening with Chimeras layer were clustered into operational taxonomic units (OTUs), based on a sequence identity threshold of 97\%, using Uclust (Edgar, 2010); drawing one sequence for each OTU, as representative, and then aligned to Greengenes (http://greengenes.lbl.gov/) using PyNast (Caporaso et al., 2010). Sequences 
representative of each OTU were taxonomically classified by BLASTn-based comparisons to the Greengenes and Silva databases within QIIME.

Bacterial 16S rRNA gene fragments ( $\sim 550$ bp) were PCR amplified using primers 907R (3'CCGTCAATTCCTTTGAGTTT- 5') and GC-357F (3'-CCTACGGGAGGCAGCAG- 5' with a 5'-end GCclamp) targeting a portion of the 16S rRNA gene that includes the hypervariable V3-V5 regions (Muyzer et al., 1993). PCR reactions were performed as previously described (Mapelli et al., 2013a). PCR amplification of alkB gene, encoding for the alkane monooxygenase, was performed on the total DNA extracted from Ancona harbor enrichments (U5-CO, U-5-DB, U5-DS, U7-CO, U7-DB, U7-DS) and from U5 and U7 sediments as previously reported (Amer et al., 2015).

For Denaturing Gradient Gel Electrophoresis (DGGE), PCR products $(\sim 100 \mathrm{ng})$ were loaded in a $0.7 \mathrm{~mm}$ polyacrylamide gel (7\% w/v acrylamide-bisacrylamide, $37.5: 1)$ containing $38 \%$ to $63 \%$ and $40 \%$ to $70 \%$ urea-formamide denaturing gradient (100\% corresponds to $7 \mathrm{M}$ urea and $40 \% \mathrm{v} / \mathrm{v}$ formamide), respectively for $16 \mathrm{~S}$ rRNA and $a l k B$ genes. The gels were run for $17 \mathrm{~h}$ at $60{ }^{\circ} \mathrm{C}$ by applying a constant voltage of $90 \mathrm{~V}$ in $1 \mathrm{X}$ Tris-acetate-EDTA (TAE) buffer. After electrophoresis, the gels were stained for $15 \mathrm{~min}$ in $1 \mathrm{X}$ TAE buffer containing 1X SYBR Green (Molecular Probes, Leiden, the Netherlands) according to manufacturer's instructions and rinsed three times for $10 \mathrm{~min}$ with distilled water. Gels images were captured using a Gel Doc 2000 apparatus (Bio-Rad, Milan, Italy). The band patterns of the DGGE gel were analyzed using Image J software and Microsoft Excel XLSTAT software (Addinsoft Inc.,New York, NY, USA) to perform a cluster analysis as previously described (Marasco et al., 2012). DGGE bands were excided from the gels of alkB gene with a sterile scalpel and eluted in $50 \mu \mathrm{l}$ of sterile Milli-Q water at $37^{\circ} \mathrm{C}$ for $3 \mathrm{~h}$. The eluted DNA was amplified by PCR using primers DalkF and DalkR and positive amplifications were sequenced by Macrogen Inc., South Korea.

\section{4 - Microcosm Enrichments}

Different enrichment cultures were established using polluted sediments as inocula and different HC molecules as the sole carbon sources. One g of sediment collected either from sampling site U5 or U7 was inoculated in minimal mineral media ONR7a supplemented by $1 \% \mathrm{v} / \mathrm{v}$ crude oil $(\mathrm{CO}), 1 \% \mathrm{v} / \mathrm{v}$ diesel oil 
(DB) or $1 \% \mathrm{w} / \mathrm{v}$ naphtalene $(\mathrm{N})$. Cycloheximide $(0.01 \% \mathrm{w} / \mathrm{v})$ was added to all the microcosms to avoid eukaryote growth. The microcosms were incubated at $30^{\circ} \mathrm{C}$ with constant shaking at $150 \mathrm{rpm}$ until turbidity appeared. In the case of diesel oil added microcosms, $1 \mathrm{~mL}$ of liquid culture collected at the interface between the diesel oil layer and the growth media aqueous phase was re-inoculated in fresh ONR7a medium aiming to enrich those bacteria adhering on the diesel droplets floating on the medium surface: this newly established microcosm was defined as "diesel surface" (DS). Total DNA was extracted from $10 \mathrm{~mL}$ of each enrichments from the cells retained on $0.2 \mu \mathrm{M}$ pore size filters, accordingly to previously described methods (Mapelli et al., 2013b).

\section{5 - Bacteria isolation and identification and evaluation of metabolic and biotechnological traits}

Bacterial isolates have been obtained in pure cultures exclusively from crude oil and diesel oil enrichments, by plating on ONR7a solid medium ten-fold dilutions of the positive enrichments, supplementing by the same $\mathrm{HC}$ source. After purification, the isolates were streaked with and without $\mathrm{HC}$ compounds and those able to grow exclusively in presence of the $\mathrm{HC}$ were selected for further characterization.

The bacteria collection was dereplicated through Internal Transcribed Spacer (ITS) PCR-fingerprinting. ITSfingerprinting was performed as previously described (Mapelli et al., 2013a) using the primers ITS-F (3'GTCGTAACAAGGTAGCCGTA-5) and ITS-R (3'-CTACGGCTAC CTTGTTACGA-5') (Daffonchio et al., 1998). One isolate for each ITS group, established basing on identical ITS-fingerprinting, was identified by partial 16S rRNA sequencing and subsequent alignment of the sequence in NCBI database. The amplification of the bacterial 16S rRNA gene was performed using the universal primer 27F (3'-AG AGTTTGATCMTGGCTCAG-5') and 1492R (3'-CTACGGCTACCTTGTTACGA-5'). The PCR amplification conditions and thermal protocol were set up as previously described (Mapelli et al., 2013a) providing a PCR amplicon of approximately 1400 bp that was partially sequenced by Macrogen Inc., South Korea.

The identified isolates were tested for the production of surfactants by drop collapse test and emulsification test. Drop collapse test was modified from the procedure previously described (Bodour and Miller-Maier, 1998). The strains were grown in ONR7a media added with crude oil (1\%) and glucose (2\%) for 1 week at 
$30^{\circ} \mathrm{C}$, than the test was performed in 96 micro-wells plates. The wells were coated with $7 \mu \mathrm{L}$ of crude oil and left to equilibrate for $24 \mathrm{~h}$ at room temperature. Twenty $\mu \mathrm{L}$ of samples were added in the center of the wells and after $1 \mathrm{~min}$ the drops were visually examinated and compared with the positive controls (SDS 1\%) and negative controls (deionized water and sterile growth media). Both the cells culture and the supernatant were tested.

Emulsification test was performed modifying the procedure previously described (Batista et al., 2006; Das et al., 1998). Cells were grown in $20 \mathrm{~mL}$ of ONR7a medium added with $1 \%$ of crude oil as the sole carbon source, at $30^{\circ} \mathrm{C}$ and with constant shaking. After 1 week of incubation cells were pelleted (4500 rpm, $10 \mathrm{~min}$, $4^{\circ} \mathrm{C}$ ) and the supernatant was used to perform the test. Three $\mathrm{mL}$ of $p$-Xylene and the same volume of supernatant of the cell culture were vortexed together for $2 \mathrm{~min}$ and the solution was left to equilibrate at room temperature for $24 \mathrm{~h}$. The height of the emulsion layer was than measured and the emulsification activity was calculated as follows: $\mathrm{EV}_{24 \mathrm{~h}}(\%)=$ (height of the emulsion layer/total height $) \times 100$. To evaluate emulsification, the height of the emulsification layer obtained from each lysate was compared with positive (SDS 1\%) and negative (sterile growth media) samples, while to evaluate the stability of the emulsion the emulsification activity value at $24 \mathrm{~h}$ was compared with the emulsification valued calculated after $48 \mathrm{~h}$ $\left(\mathrm{EV}_{48 \mathrm{~h}}\right)$.

The capacity of the isolates to form biofilm was determined by the crystal violet staining assay (Antoniani et al., 2010). Bacteria were grown for 72 hours in liquid ONR7a medium added with $1 \%$ Na-pyruvate, at $30^{\circ} \mathrm{C}$ in 96 wells, flat bottom, polystyrene microtiter plates. After the growth, the optical density $600 \mathrm{~nm}\left(\mathrm{OD}_{600 \mathrm{~nm}}\right)$ of the cell culture was measured. The liquid culture was then removed, and cells attached to the microtiter plates were washed gently with PBS and stained for 10 min with $0.03 \%$ crystal violet, thoroughly washed with PBS and water, and dried. For semiquantitative determination of biofilms, crystal violet stained cells were re-suspended in $0.2 \mathrm{ml}$ of $95 \%$ ethanol by pipetting. The $\mathrm{OD}_{600 \mathrm{~nm}}$ of crystal violet stained biofilm cells was determined and normalized to $\mathrm{OD}_{600 \mathrm{~nm}}$ of cells from the corresponding liquid cultures; this value is defined as "adhesion units". The isolates were considered biofilm producers if they showed an OD value of at least 0.12 . If the OD exceeded 0.240, they were classified as strongly adherent. Strains displaying OD values greater than 0.12 but less than 0.240 were classified as weakly adherent (Amer et al., 2015). 
The uricolytic activity of the isolates was tested with a modification of a previously described protocol (Morales-Jiménez et al., 2013). Cells were grown in ONR7a liquid medium added with 1\% Na-pyruvate as the sole carbon source. After 4 days of incubation at $30^{\circ} \mathrm{C}, 10 \mu \mathrm{L}$ of cell cultures were spotted in triplicates on ONR7a (pH6.5) agar plates added with 1\% Na-pyruvate as carbon sources and $0.5 \%$ uric acid and incubated at $30^{\circ} \mathrm{C}$. Active strains determined the formation of a clear halo around the colony. The hydrolytic activity was defined as the diameter of the colony plus the clear zone divided by the diameter of the colony.

Catechol 2,3 dioxygenase (C2,3O) activity was determined modifying a previously described method (Margesin et al., 2003). Ten $\mu \mathrm{L}$ of a solution containing $90 \mathrm{mM}$ catechol in $50 \mathrm{mM}$ Tris-acetate buffer (pH 7.5) was added over the cells grown on agar plates. The presence of $\mathrm{C} 2,3 \mathrm{O}$ activity resulted in the formation of a green-brownish color within $2 \mathrm{~h}$ at room temperature.

\section{6 - Nucleotide sequence accession numbers}

Nucleotide sequences were edited in Chromas Lite 2.01 (http://www.technelysium.com.au) and subjected to BLAST search (http://blast.ncbi.nlm.nih.gov/Blast.cgi). The partial 16S rRNA gene sequences obtained from the bacterial isolates are available at ENA under accession numbers LN872945 - LN872962. All original non-chimeric 16S rRNA hypervariable tag 454 sequences are archived at the EBI European Read Archive under accession number PRJEB10119.

\section{7 - Statistical analyses}

Significant differences in i) environmental chemical-physical parameters and ii) the bacterial community richness between control and polluted sediments were investigated by permutational analysis of variance (PERMANOVA) (Anderson, 2001).

Non-metric multidimensional scaling (nMDS) was carried out as visual information to explore similarities between bacteria communities richness evaluated through ARISA fingerprinting. The same set of biotic data was used, together with the environmental parameters recorded at each site, in the distance-based multivariate analysis for a linear model (DistLM) (Anderson, 2002) to determine which significant 
environmental variables explain the observed similarity among the samples. The Akaike Information Criterion (AIC) was used to select the predictor variables. The contribution of each environmental variable was assessed using 'marginal tests' to assess the statistical significance and percentage contribution of each variable. A distance-based redundancy analysis (dbRDA) was used for graphical visualization of the DistLM results. All the statistical tests were performed by PRIMER v. 6.1 (Clarke and Gorley, 2006), PERMANOVA+ for PRIMER routines (Anderson et al., 2008).

\section{RESULTS}

\section{1- Physico-chemical analyses}

Minor differences of physical characteristics were found between the collected sediments (Table 1). The granulometric analysis of the sediments revealed the dominance of the clay fraction (on average 55\%) and the reduced presence of gravel, while the $\mathrm{pH}$ values in the samples ranged between 7.47 and $7.85-$ accordingly to the typical $\mathrm{pH}$ value of coastal marine environments, which is comprised between 7.5 and 8.4 (Chester and Jickells, 2012). The redox potential of the samples ranged between 28 and $247.3 \mathrm{mV}$, showing that sediments were oxygenated in the surface layers.

All the sediments collected in the harbor area displayed high concentrations of heavy $\mathrm{HC}(\mathrm{C}>12)$, ranging from 65.3 to $316.5 \mathrm{mg} / \mathrm{kg}$ while in the offshore stations the heavy HCs concentration showed a lower average value of $34.98 \mathrm{mg} / \mathrm{kg}$ (Table 2). The concentration of polycyclic aromatic hydrocarbons (PAHs) measured in the sediments was high in seven of the ten sites analyzed inside the harbor area, showing the highest concentration at stations U1 and U4 (Table 2). In addition to HC, we also investigated the concentrations of heavy metals in the sediments, which tend to precipitate and to be absorbed by sediments particles. Their concentration was higher than the Italian law limits for nickel, chromium, cadmium and lead (Table 2). Cadmium concentration was high in all the stations located inside the harbor, differently from what observed at the offshore stations. Sediments were highly concentrated of chromium in almost all the sites independently from their location, displaying low values only in three of the offshore sites, while the highest values were detected at stations U2 and U3 inside the harbor. Nickel was present at high 
concentration in all the sampling stations while a high concentration of lead was detected only at site U1

(Table 2). The statistical PERMANOVA analysis was applied on the physico-chemical matrix showing a significant difference $(\mathrm{p}=0.0089)$ between the sediments collected inside the harbor and those collected offshore, thus allowing to define the two sites as polluted and pristine stations, respectively.

\subsection{Microbial community richness}

Prokaryote abundance in all the sampling sites was estimated through SYBR Green staining and ranged between $4.04 \times 10^{8}$ (U7) and $1.13 \times 10^{9}$ (U5) cell/g d.s. in the sediments collected from the polluted area, while it decreased slightly in the offshore control sites, where prokaryote cells ranged from $9.76 \times 10^{7}$ (C5) to $7.46 \times 10^{8}(\mathrm{C} 1)$ cell/g d.s (Table 1).

The total bacterial communities of pristine and polluted sediments were investigated through ARISA fingerprinting. ARISA profiles of the polluted sediments comprised between 38 and 78 OTUs (i.e. ARISA peaks) in the sites U2 and U3 respectively, while those obtained from the offshore control sites showed a higher numbers of OTUs ranging between 87 (C4) and 94 (C2). This result suggests the presence of a higher number of different taxa in the pristine stations respect to the polluted ones. nMDS analysis based on the ARISA fingerprints (Figure 1b) showed a clear separation between the bacterial communities inhabiting polluted and control sites (stress value $=0.01$ ). PERMANOVA test indicated that the richness of the sediment-dwelling bacterial communities from the pristine and polluted areas of the Ancona harbor was significantly different $(\mathrm{p}=0.0003)$.

A DistLM analysis was applied to identify the environmental variables influencing the bacterial community richness in the polluted and control sites of the Ancona harbor. The results of DistLM showed that the variation of community's richness according to ARISA profiles was significantly related to five environmental variables (Figure 1c). Among the chemical components, cadmium ( $p=0.0001)$, chromium ( $p$ $=0.0001)$, copper $(\mathrm{p}=0.0453), \mathrm{HCs} \mathrm{C}>12(\mathrm{p}=0.0055)$ and TOC $(\mathrm{p}=0.0043)$ were significant, while none of the measured physical properties was significantly related to the richness values. The two axes of the dbRDA explained $86.0 \%$ of the total variation (Figure 1c). 
3.3 - Microbial diversity in microcosm enrichments established with different pollutants as the sole carbon source

HC-degrading bacterial cultures were enriched from the polluted sediments collected in the sites U5 and U7, characterized respectively by the highest and the lowest value of prokaryote cell abundance (Table 1). The number of $\mathrm{HC}$ degrading bacteria inhabiting these sediments was evaluated through the MPN method and corresponded to $7.3 \times 10^{2}$ cell/g d.s. in site U5 and $4.3 \times 10^{3}$ cell/g d.s. in site U7.

The structure of the original sediment and the microcosm enriched bacterial communities was evaluated by applying two molecular techniques targeting 16S rRNA gene, PCR-DGGE fingerprinting and barcoded pyrosequencing. PCR-DGGE analysis showed the occurrence of different and more complex band patterns in the original sediments than in the established enrichments (Figure 2a). Overall, independently from the sediment origin, the PCR-DGGE profiles were more similar when diesel or crude oil were added in the medium, while naphthalene enrichment cultures selected more specific bacterial populations, as confirmed by PCR-DGGE cluster analysis (Figure 2a-b).

Rarefaction curves of pyrosequencing data showed that all the libraries reached saturation and covered the whole bacterial diversity within the samples (Figure S2). Both the sediment samples showed similar Shannon indexes (U5: H' = 8.201; U7: H' = 8.363), higher than those detected in the examined U5 enrichments with the different pollutants (U5-N: H' = 4.717; U5-CO: H' = 4.589; U5-DB: H' = 3.704). Principal coordinates analyses (PCoA), explaining $68.71 \%$ of the diversity observed (Figure 3a), showed the differential clustering of environmental and cultivated bacterial communities. Along PC1, explaining $43.52 \%$ of the diversity, it was possible to identify two groups, represented by the environmental samples U5 and U7 and diesel, crude oil and naphthalene microcosms, respectively. On the other side, along PC2, the naphthalene enrichment culture U5-N was well separated from the other enrichments. The bacterial community of site U5 was dominated by four different phyla (Proteobacteria, 52.82\%, that covered more than half of the total diversity; Firmicutes, 15.98\%; Bacteroidetes, 9.4\% and Fusobacteria, 5.17\%) while U7 was dominated only by three different phyla (Proteobacteria, 38.21\%; Firmicutes, 31.9\% and Bacteroidetes, 9.7\%) (Figure 3c, Table S1). Both sediments were dominated by Gammaproteobacteria and Clostridia classes (Figure 3d, Table S1), the 
former representing $38 \%$ of the bacterial populations of sediment U5 and $23 \%$ of sediment U7, while Clostridia represented respectively the $16 \%$ and $31 \%$ of the bacterial community.

The established microcosms hosted a less diverse bacterial community (Figure 3, Table S1). Only four out of the 20 different phyla identified in the U5 sediment were present in the enrichment U5-DB, three in U5-CO and four in U5-N (Figure 3c). Diesel and crude oil microcosms were dominated by Proteobacteria (98\%), while the phylum Firmicutes was the most abundant (64\%) in the naphthalene enrichment, followed by Proteobacteria (34\%). The low level of bacterial diversity occurring in the microcosms could be observed also at finer phylogenetic scale (Figure 3d): Gammaproteobacteria dominated both diesel and crude oil enrichments (98\%), while naphthalene enrichment comprised mostly Bacilli (64.5\%) and Gammaproteobacteria (31\%). The genera that dominated diesel and crude oil microcosms were Alcanivorax and Marinobacter, which together represented about $70 \%$ of the bacterial diversity, while the naphthalene enrichment was mainly dominated by Bacillus (55.6\%) and Halomonas (15.5\%) genera (Figure S1).

PCR-DGGE profiles of the alkB gene in the sediments (U5 and U7) were more complex in the diesel and crude oil microcosms, indicating a more diverse HC-degrading microbial community compared to the communities enriched in laboratory microcosms (Figure 2c-d). All the identified alkB gene sequences were associated to few hydrocarbonoclastic bacterial species typically spread in marine polluted ecosystems, i.e. M. hydrocarbonoclasticus, M. adhearence, Alcanivorax. hodgenensis and A. borkumensis, (Table S2).

\subsection{Hydrocarbon degrading strains}

A collection of HC degrading bacteria was established from the U5 and U7 microcosms enriched on diesel and crude oil. The isolated strains belonged to few bacterial species (Table 3). Despite the highly diverse bacterial community detected by $16 \mathrm{~S}$ rRNA gene pyrosequencing in the original sediments, only the species A. borkumenis (26 isolates), M. hydrocarbonoclasticus (3) and Pseudomonas pachastrellae (1) were isolated from the enrichments inoculated with sediment U5 whereas A. borkumenis (29) and Marinobacter excellens (1) were obtained in pure cultures from enrichments inoculated with sediment U7.

The isolates were clustered in different phylogenetic groups on the bases of their ITS fingerprints and at least one representative of each cluster was tested for biotechnological properties related to bioremediation, 
including production of biosurfactants and bioemulsifiers, biofilm formation and degradation of uric acid and catechol (Table 3). Drop collapse test indicated that none of the strains produced biosurfactants. Nonetheless almost all of them (with the exception of U5-DS4, U7-CO6 and U7-DB8) produced emulsifying molecules with different levels of activity and stability (Table 3). Among the tested strains, the relative emulsification activity at 24 hours ranged between $5.2 \%$ of A. borkumensis strain U5-DS9 and $48.3 \%$ of A. borkumensis U7-DS3, while the stability of the emulsification measured at 48 hours varied between $100 \%$ of $A$. borkumensis, M. hydrocarbonoclasticus and P. pachastrellae representatives (Table 3) and $66.5 \%$ of $A$. borkumensis U5-DB11. Most of the isolates were capable to form biofilm (Table 3), a phenotype that could enhance their fitness in the sediment environment. The majority of the strains (89\%) could be classified as strongly adherent and among them A. borkumensis U5-DB1 was the best performer. Four strains (A. borkumensis U7-CO14 and M. hydrocarbonoclasticus strains U5-DB8, U5-DB14 and U5-DB18) were also able to degrade uric acid and all of the strains were positive for the catechol 2,3 dioxygenase activity (Table $3)$.

\section{DISCUSSION}

This study investigated the influence of pollution on the assemblage of the bacterial populations thriving in natural and polluted sediments of the Ancona harbor, and provides isolated bacteria that may play role in ABA. The sediment chemical analysis indicated high concentrations of crude oil-derived long chain aliphatic HC (C>12), PAHs and heavy metals (Table 2). Heavy metals are of particular relevance in ABA approach since they can inhibit biodegradation and bioremediation of the organic pollutants, because of their toxicity toward microorganisms. In the Ancona harbor cadmium, chromium, nickel, and lead were retrieved in several samples in high concentrations (Table 2). The high level of heavy HCs in the harbor area suggested an input from ships and other harbor activities, while the presence of high concentration of PAHs in the stations $\mathrm{U} 1$ and $\mathrm{U} 4$ is probably due to the impact of a fuel station located nearby these sites. The evaluation of the total prokaryotic cell number in these sediments revealed that the contamination level did not impact bacterial abundance, since the retrieved values (Table 1) are in accordance with previously published data at 
the sediment-water interface layers of the Adriatic sea (Molari et al., 2012) and containing high levels of TOCs.

Pollutants' concentrations resulted to be pivotal drivers in shaping the assembly of the sediment bacterial communities as determined by ARISA fingerprinting. Five of the evaluated environmental parameters, namely the concentration of cadmium, copper, chromium, HCs $(C>12)$ and TOC were related with the richness of the bacterial communities (Figure 1c) confirming that crude oil components and heavy metals are among the main factors influencing the sediment bacterial communities assembly.

Due to their different physico-chemical parameters and microbiological composition, the sediments collected at stations U5 and U7 were chosen as the starting inocula for the cultivation-based experiments. Station U7 showed a higher percentage of gravel and displayed higher redox potential indicating higher oxygenation (Table 1). Moreover, the sediments collected at station U7 were the most polluted in term of HC $(\mathrm{C}>12)$ concentration and, in addition, displayed a PAHs concentration about tenfold higher than in U5 (Table 2). The sediments were also microbiologically different: U7 showed a lower concentration of total prokaryotic cell (Table 1), but a higher amount of HC-degrading bacteria than U5. Cultivable HC degrading microbes were counted by the Most Probable Number (MPN) assay, by adding crude oil as the sole carbon source, thus providing to the cells the maximum set of different $\mathrm{HC}$ molecules. In station U7 the number of cultivable HC-degrading bacteria was higher than in station U5, correlating to a higher level of HC pollution. This is a further evidence that the pollution level in the sediments selects for peculiar bacterial communities, able to utilize the organic pollutants as growth substrate.

Both PCR-DGGE (Figure 2a, b) and pyrosequencing (Figure 3) of 16S rRNA gene confirmed the selection of specific bacterial communities in the established microcosms after the addition of the different HCs and indicated a high specialization toward bacterial taxa involved in their degradation. The number of phyla detected through pyrosequencing decreased from 20, identified in U5 sediment, to maximum 4 in the naphthalene enriched microcosm (Table S1). Proteobacteria and Firmicutes, the bacterial phyla prevailing in the sediments, reached in the enrichments the quite totality of the communities, covering about $98 \%$ of the total diversity. Both phyla comprise several phylogenetic groups involved in the aerobic degradation of HCs (Head et al., 2006). Coherently with the high pollution level of the Ancona harbor, the sediments collected at U5 and U7 sites were dominated by Gammaproteobacteria and Clostridia, nonetheless only few of the major 
genera known to be capable of HC degradation have been identified in the established 16S rRNA gene pyrotag libraries. For instance, Oleispira was detected only in the sediment U7, where it represented $1 \%$ of the total bacterial community, while members of the family Alteromonadaceae - including the ubiquitous HC-degrading genus Marinobacter - were detected in the sediment U5 at a very low percentage (Table S1). The hydrocarbonoclastic genus Alcanivorax was not detected in both the original polluted sediments although Alcanivorax and Marinobacter genera were strongly enriched in the U5 diesel and crude oil microcosms. This result pointed out that these genera were present in the original U5 sediment at a very low titer and below the detection limit of the used techniques (Table S1). A high percentage of the sequences retrieved from sediments belonged to unclassified bacterial phyla, This percentage is even higher if we describe the bacterial community at lower phylogenetic level (e.g. genera level) (Figure 3, Table S1), highlighting the high potential of Ancona harbor sediments to retrieve novel and yet uncultured microbial resources. In the enrichment microcosms, nevertheless, the majority of the sequences belonged to already described taxa, indicating that the majority of the HC degraders present in Ancona harbor sediments are recalcitrant to cultivation.

Alcanivorax and Marinobacter belong to the Gammaproteobacteria class whose dominance within the enriched microcosms can be expected since it comprises many of the hydrocarbonoclastic bacteria responsible for the first steps of $\mathrm{HC}$ degradation (Head et al., 2006; Yakimov et al., 2007). The analysis of alkB gene diversity in the enriched microcosms (Figure 2c-d) further confirmed the more complex functional diversity of the sediment samples than in the microcosms, and identified Marinobacter and Alcanivorax as the genera main players of alkane degradation in the sediment of the Ancona harbor (Table S2). Naphthalene enrichment was dominated by Bacillus (55.57\%) and Halomonas (15.52\%) (Table S1), both known to be involved in the degradation of PAHs molecules (Kostka et al., 2011; McGenity et al., 2012).

The culture conditions adopted for the isolation of HC-degrading strains from the enriched microcosms allowed the isolation of only four species, A. borkumensis, M. hydrocarbonoclasticus, M. excellens and $P$. pachastrellae (Table 3). Such a low phylogenetic diversity within the bacteria collection is presumably due to the enrichment culture conditions, which favored the selection of few fast growing and very specialized hydrocarbonoclastic microorganisms already reported as the first to bloom after an oil spill (Head et al., 2006 and references therein). One of the physiological traits that makes Alcanivorax highly competent is its 
capability to produce biosurfactants that enhance HCs bioavailability. Members of Marinobacter genus are able to use a wide variety of HCs (Gauthier et al., 1992; Gorshkova et al., 2003), while Pseudomonas spp. are widespread environmental microorganisms isolated from a variety of natural sources including marine sediments and seawater (Pucci et al., 2012; Velmurugan et al., 2011) and capable to use a wide range of carbon sources (Kostka et al., 2011; Mahjoubi et al., 2013; Mulet et al., 2011).

Surprisingly, despite the capacity to grow on HCs and the prompt growth in the different enrichment cultures, none of the tested isolates was capable to produce biosurfactants in the adopted conditions (Table 3). However, $83 \%$ of the tested strains were able to produce bioemulsifing factors, another class of surfaceactive compounds that reduces the interfacial tension between immiscible liquids. Indeed, while biosurfactants, in most cases, have also a certain degree of emulsifying activity, bioemulsifiers are not necessarily able to act as biosurfactant molecules (Karant et al., 1999), but their production is nonetheless considered an advantageous trait in oil polluted environments (Batista et al., 2006).

The isolates from the different enrichment cultures showed interesting biotechnological properties for applications in $\mathrm{ABA}$. The lack of nitrogen and phosphorus in marine environments is one of the main factors negatively affecting the growth of HC-degrading bacteria in polluted sites. Recently, the use of uric acid as a natural fertilizer for the bioremediation of marine oil pollution has been proposed to overcome this limitation (Ron and Rosenberg, 2014) and a microcosm-scale study showed its rapid conversion to ammonium and a role in the selection of microbial communities encompassing known hydrocarbonoclastic bacteria (Bargiela et al., 2015b; Gertler et al., 2015). Four of the tested isolates (one A. borkumensis and three $M$. hydrocarbonoclasticus) were capable to degrade uric acid suggesting their potential to be responsive to uric acid amendment in bioremediation trials. Sixty six percent of the tested strains showed to be capable of biofilm formation. Cells that grow as biofilm have higher chances to survive and adapt to the difficult condition of polluted environments, being protected within the biofilm matrix and thanks to the beneficial interactions occurring between the different microorganisms inhabiting the biofilm (Singh et al., 2006). All the strains proved to be able to degrade catechol, a central metabolite in aromatic HC degradation pathways (Fuentes et al., 2014). Taken together, all the above phenotypic traits render the isolated bacteria interesting for application in polluted natural environments, for instance in ABA. 
Our results, supported by the molecular ecology analyses and the cultivation approach, indicated that in the sediments of the Ancona harbor heavy metals and HCs drive the selection of specific bacterial communities with $\mathrm{HC}$ degrading potential. The bacterial genera enriched in the sediment present interesting properties for application in the ABA approach. Nonetheless, the results also remarked the need for innovative cultivationdependent strategies to bring into culture the new taxa identified in the sediments by the cultivationindependent pyrosequencing analyses. This would allow to retrieve a larger spectrum of marine bacterial diversity to further expand the potential for $\mathrm{ABA}$ approaches in marine sites with multiple contaminations.

\section{Acknowledgments}

This work was funded by FP-7 projects ULIXES (No. 266473, "Unravelling and exploiting Mediterranean Sea microbial diversity and ecology for xenobiotics' and pollutants' clean up”) and Kill Spill (No. 312139, "Integrated Biotechnological Solutions for Combating Marine Oil Spills"). The authors thank the support of King Abdullah University of Science and Technology (baseline research funds to D.D.). F.M. was supported by Università degli Studi di Milano, DeFENS, European Social Found (FSE) and Regione Lombardia (contract "Dote Ricerca").

\section{References}

Amer, R.A., Mapelli, F., Gendi, H.M. El, Barbato, M., Goda, D.A., Corsini, A., Cavalca, L., Fusi, M., Borin, S., Daffonchio, D., Abdel-fattah, Y.R., 2015. Bacterial Diversity and Bioremediation Potential of the Highly Contaminated Marine Sediments at El-Max District ( Egypt, Mediterranean Sea ). Biomed Res. Int.

Anderson, M.J., 2002. DISTLM v.2: a FORTRAN computer program to calculate a distance-based multivariate analysis for a linear model.

Anderson, M.J., 2001. A new method for non-parametric multivariate analysis of variance. Austral Ecol. $26,32-46$. doi:10.1111/j.1442-9993.2001.01070.pp.x

Anderson, M.J., Gorley, R.N., Clarke, K.R., 2008. +for PRIMER: Guide to Software and Statistical Methods, PRIMERE. Plymouth, UK.

Antoniani, D., Bocci, P., Macląg, A., Raffaelli, N., Landini, P., 2010. Monitoring of diguanylate cyclase activity and of cyclic-di-GMP biosynthesis by whole-cell assays suitable for high-throughput screening of biofilm inhibitors. Appl. Microbiol. Biotechnol. 85, 1095-1104. doi:10.1007/s00253-009-2199-x

Bargiela, R., Mapelli, F., Rojo, D., Chouaia, B., Tornés, J., Borin, S., Richter, M., Del Pozo, M. V., Cappello, S., Gertler, C., Genovese, M., Denaro, R., Martínez-Martínez, M., Fodelianakis, S., Amer, R.A., Bigazzi, D., Han, X., Chen, J., Chernikova, T.N., Golyshina, O. V., Mahjoubi, M., Jaouanil, A., Benzha, F., Magagnini, M., Hussein, E., Al-Horani, F., Cherif, A., Blaghen, M., Abdel-Fattah, Y.R., Kalogerakis, N., Barbas, C., Malkawi, H.I., Golyshin, P.N., Yakimov, M.M., Daffonchio, D., Ferrer, M., 2015a. Bacterial population and biodegradation 
potential in chronically crude oil-contaminated marine sediments are strongly linked to temperature. Sci. Rep. 5, 11651. doi:10.1038/srep11651

Bargiela, R.,Gertler, C.,Magagnini, M., Mapelli, F.,Chen, J.,Daffonchio, D., Golyshin, P.N., Ferrer, M., 2015b Degradation network reconstruction in uric acid and ammonium amendments in oil-degrading marine microcosms guided by metagenomic data.Front.Microbiol.6:1270. doi:10.3389/fmicb.2015.01270

Batista, S.B., Mounteer, a. H., Amorim, F.R., Tótola, M.R., 2006. Isolation and characterization of biosurfactant/bioemulsifier-producing bacteria from petroleum contaminated sites. Bioresour. Technol. 97, 868875. doi:10.1016/j.biortech.2005.04.020

Bodour, A. a., Miller-Maier, R.M., 1998. Application of a modified drop-collapse technique for surfactant quantitation and screening of biosurfactant-producing microorganisms. J. Microbiol. Methods 32, 273-280. doi:10.1016/S0167-7012(98)00031-1

Caporaso, J.G., Kuczynski, J., Stombaugh, J., Bittinger, K., Bushman, F.D., Costello, E.K., Fierer, N., Peña, A.G., Goodrich, J.K., Gordon, J.I., Huttley, G.A., Kelley, S.T., Knights, D., Koenig, J.E., Ley, R.E., Lozupone, C.A., McDonald, D., Muegge, B.D., Pirrung, M., Reeder, J., Sevinsky, J.R., Turnbaugh, P.J., Walters, W.A., Widmann, J., Yatsunenko, T., Zaneveld, J., Knight, R., 2010. QIIME allows analysis of high-throughput community sequencing data. Nat. Methods 7, 335-6. doi:10.1038/nmeth.f.303

Cappello, S., Caruso, G., Zampino, D., Monticelli, L.S., Maimone, G., Denaro, R., Tripodo, B., Trousselier, M., Yakimov, M., Giuliano, L., 2006. Microbial Community dynamics during assay of harbour oil spill bioremediation: a microscale simulation study. J. Appl. Microbiol. 102, 184-194.

Cardinale, M., Brusetti, L., Quatrini, P., Borin, S., Puglia, A.M., Rizzi, A., Zanardini, E., Sorlini, C., Corselli, C., Daffonchio, D., 2004. Comparison of different primer sets for use in automated ribosomal intergenic spacer analysis of complex bacterial communities. Appl. Environ. Microbiol. 70, 6147-6156.

Chakravorty, S., Helb, D., Burday, M., Connell, N., Alland, D., 2007. A detailed analysis of 16S ribosomal gene segments for the diagnosis of pathogenic bacteriaNo Title. J. Microbiol. Methods 69, 330-339.

Chester, R., Jickells, T., 2012. Marine Geochemistry. Blackwell Publishing.

Clarke, K., Gorley, R., 2006. PRIMER v6. User manual/tutorial. Plymouth routine in multivariate ecological research.

Daffonchio, D., Borin, S., Frova, G., Manachini, P., Sorlini, C., 1998. PCR fingerprinting of whole genomes, the spacers between the 16S and 23S rRNA genes and of intergenic tRNA gene regions reveal a different intraspecific genomic variability of Bacillus cereus and Bacillus licheniformis (vol 48, pg 107, 1998). Int. J. Syst. Bacteriol. 48, 1081-1081.

Daffonchio, D., Ferrer, M., Mapelli, F., Cherif, A., Lafraya, Á., Malkawi, H.I., Yakimov, M.M., Abdel-Fattah, Y.R., Blaghen, M., Golyshin, P.N., Kalogerakis, N., Boon, N., Magagnini, M., Fava, F., 2013. Bioremediation of Southern Mediterranean oil polluted sites comes of age. N. Biotechnol. 30, 743-748. doi:10.1016/j.nbt.2013.05.006

Daffonchio, D., Mapelli, F., Cherif, A., Malkawi, H.I., Yakimov, M.M., Abdel-Fattah, Y.R., Blaghen, M., Golyshin, P.N., Ferrer, M., Kalogerakis, N., Boon, N., Magagnini, M., Fava, F., 2012. ULIXES, unravelling and exploiting Mediterranean Sea microbial diversity and ecology for xenobiotics' and pollutants' clean up. Rev. Environ. Sci. Biotechnol. 11, 207-211. doi:10.1007/s11157-012-9283-x

Das, M., Das, S.K., Mukherjee, R.K., 1998. Surface active properties of the culture filtrates of a micrococcus species grown on n-alkanes and sugars. Bioresour. Technol. 63, 231-235.

Dell'Anno, A., Beolchini, F., Gabellini, M., Rocchetti, L., Pusceddu, A., Danovaro, R., 2009. Bioremediation of petroleum hydrocarbons in anoxic marine sediments: Consequences on the speciation of heavy metals. Mar. Pollut. Bull. 58, 1808-1814. doi:10.1016/j.marpolbul.2009.08.002 
Dyksterhouse, S.E., Gray, J.P., Herwig, R.P., Lara, J.C., Staley, J.T., 1995. Cycloclasticus pugetii gen. nov., sp. nov., an aromatic hydrocarbon-degrading bacterium from marine sediments. Int. J. Syst. Bacteriol. 45, 116-123.

Edgar, R.C., 2010. Search and clustering orders of magnitude faster than BLAST. Bioinformatics 26, $2460-1$. doi:10.1093/bioinformatics/btq461

Fodelianakis, S., Antoniou, E., Mapelli, F., Magagnini, M., Nikolopoulou, M., Marasco, R., Barbato, M., Tsiola, A., Tsikopoulou, I., Giaccaglia, L., Mahjoubi, M., Jaouani, A., Amer, R., Hussein, E., Al-Horani, F.A., Benzha, F., Blaghen, M., Malkawi, H.I., Abdel-Fattah, Y., Cherif, A., Daffonchio, D., Kalogerakis, N., 2015. Allochthonous bioaugmentation in ex situ treatment of crude oil-polluted sediments in the presence of an effective degrading indigenous microbiome. J. Hazard. Mater. 287, 78-86.

Fuentes, S., Méndez, V., Aguila, P., Seeger, M., 2014. Bioremediation of petroleum hydrocarbons: Catabolic genes, microbial communities, and applications. Appl. Microbiol. Biotechnol. 98, 4781-4794. doi:10.1007/s00253-0145684-9

Gaudette E., Flight R., Toner L., F.W., 1974. An inexpensive titration method for the determination of organic carbon in recent sediments. Sediment. Petrol. 44, 249-53.

Gauthier, M.J., Lafay, B., Christen, R., Fernandez, L., Acquaviva, M., Bonin, P., Bertrand, J.C., 1992. Marinobacter hydrocarbonoclasticus gen. nov., sp. nov., a new, extremely halotolerant, hydrocarbon-degrading marine bacterium. Int. J. Syst. Bacteriol. 42, 568-576. doi:10.1099/00207713-42-4-568

Gertler, C., Bargiela, R., Mapelli, F., Han, X., Chen, J., Hai, T., Amer, R. a., Mahjoubi, M., Malkawi, H., Magagnini, M., Cherif, A., Abdel-Fattah, Y.R., Kalogerakis, N., Daffonchio, D., Ferrer, M., Golyshin, P.N., 2015. Conversion of Uric Acid into Ammonium in Oil-Degrading Marine Microbial Communities: a Possible Role of Halomonads. Microb. Ecol. doi:10.1007/s00248-015-0606-7

Gorshkova, N.M., Ivanova, E.P., Sergeev, A.F., Zhukova, N. V., Alexeeva, Y., Wright, J.P., Nicolau, D. V., Mikhailov, V. V., Christen, R., 2003. Marinobacter excellens sp. nov., isolated from sediments of the Sea of Japan. Int. J. Syst. Evol. Microbiol. 53, 2073-2078. doi:10.1099/ijs.0.02693-0

Head, I.M., Jones, D.M., Röling, W.F.M., 2006. Marine microorganisms make a meal of oil. Nat. Rev. Microbiol. 4, 173-182. doi:10.1038/nrmicro1348

Hosokawa, R., Nagai, M., Morikawa, M., Okuyama, H., 2009. Autochthonous bioaugmentation and its possible application to oil spills. World J. Microbiol. Biotechnol. 25, 1519-1528. doi:10.1007/s11274-009-0044-0

Karant, N.G.K., Deo, P.G., Veenanadig, N.K., 1999. Microbial production of biosurfactant and their importance. Curr. Sci. 77, 116-126.

Kostka, J.E., Prakash, O., Overholt, W.A., Green, S.J., Freyer, G., Canion, A., Delgardio, J., Norton, N., Hazen, T.C., Huettel, M., 2011. Hydrocarbon-degrading bacteria and the bacterial community response in gulf of Mexico beach sands impacted by the deepwater horizon oil spill. Appl. Environ. Microbiol. 77, 7962-74. doi:10.1128/AEM.05402-11

Mahjoubi, M., Jaouani, A., Guesmi, A., Ben Amor, S., Jouini, A., Cherif, H., Najjari, A., Boudabous, A., Koubaa, N., Cherif, A., 2013. Hydrocarbonoclastic bacteria isolated from petroleum contaminated sites In Tunisia: Isolation, identification and characterization of the biotechnological potential. N. Biotechnol. 30, 723-733. doi:10.1016/j.nbt.2013.03.004

Mapelli, F., Marasco, R., Rolli, E., Barbato, M., Cherif, H., Guesmi, A., Ouzari, I., Daffonchio, D., Borin, S., 2013. Potential for plant growth promotion of rhizobacteria associated with Salicornia growing in Tunisian hypersaline soils. Biomed Res. Int. 2013, 248078. doi:10.1155/2013/248078

Mapelli, F., Varela, M.M., Barbato, M., Alvariño, R., Fusi, M., Álvarez, M., Merlino, G., Daffonchio, D., Borin, S., 2013. Biogeography of planktonic bacterial communities across the whole Mediterranean Sea. Ocean Sci. 9, 585595. doi:10.5194/os-9-585-2013 
Marasco, R., Rolli, E., Ettoumi, B., Vigani, G., Mapelli, F., Borin, S., Abou-Hadid, A.F., El-Behairy, U.A., Sorlini, C., Cherif, A., Zocchi, G., Daffonchio, D., 2012. A drought resistance-promoting microbiome is selected by root system under desert farming. PLoS One 7, e48479. doi:10.1371/journal.pone.0048479

Margesin, R., Gander, S., Zacke, G., Gounot, A.M., Schinner, F., 2003. Hydrocarbon degradation and enzyme activities of cold-adapted bacteria and yeasts. Extremophiles 7, 451-458. doi:10.1007/s00792-003-0347-2

McGenity, T.J., Folwell, B.D., McKew, B. a, Sanni, G.O., 2012. Marine crude-oil biodegradation: a central role for interspecies interactions. Aquat. Biosyst. 8, 10. doi:10.1186/2046-9063-8-10

Mei, M.L., Danovaro, R., 2004. Virus production and life strategies in aquatic sediments. Limnol. Oceanogr. 49, 459470.

Mirto, S., Danovaro, R., 2004. Meiofaunal colonisation on artificial substrates: A tool for biomonitoring the environmental quality on coastal marine systems. Mar. Pollut. Bull. 48, 919-926.

doi:10.1016/j.marpolbul.2003.11.016

Molari, M., Giovannelli, D., D’Errico, G., Manini, E., 2012. Factors influencing prokaryotic community structure composition in sub-surface coastal sediments. Estuar. Coast. Shelf Sci. 97, 141-148. doi:10.1016/j.ecss.2011.11.036

Morales-Jiménez, J., Vera-Ponce de León, A., García-Domínguez, A., Martínez-Romero, E., Zúñiga, G., HernándezRodríguez, C., 2013. Nitrogen-Fixing and Uricolytic Bacteria Associated with the Gut of Dendroctonus rhizophagus and Dendroctonus valens (Curculionidae: Scolytinae). Microb. Ecol. 66, 200-210. doi:10.1007/s00248-013-0206-3

Mulet, M., David, Z., Nogales, B., Bosch, R., Lalucat, J., García-Valdés, E., 2011. Pseudomonas diversity in crude-oilcontaminated intertidal sand samples obtained after the prestige oil spill. Appl. Environ. Microbiol. 77, 10761085. doi:10.1128/AEM.01741-10

Muyzer, G., Dewaal, E., Uitterlinden, A., 1993. Profiling of complex microbial-populations by denaturing gradient gelelectrophoresis analysis of polymerase chain reaction-amplified genes-coding for 16S ribosomal-RNA. Appl. Environ. Microbiol. 59, 695-700.

Nikolopoulou, M., Pasadakis, N., Kalogerakis, N., 2013. Evaluation of autochtonous bioaugmentation and biostimulation during microcosm-simulated oil spills. Mar. Pollut. Bull. 72, 165-173.

Pucci, G.N., Acuña, a J., Tonin, N.L., Tiedemann, M.C., Pucci, O.H., 2012. Diversity of culturable marine bacteria on the coastline of the central area of San Jorge Gulf, Argentina [Diversidad de las bacterias cultivables de la costa del centro del Golfo San Jorge, Argentina]. Rev. Biol. Mar. Oceanogr. 47, 367-371.

Ron, E.Z., Rosenberg, E., 2014. Enhanced bioremediation of oil spills in the sea. Curr. Opin. Biotechnol. 27, $191-194$. doi:10.1016/j.copbio.2014.02.004

Singh, R., Paul, D., Jain, R.K., 2006. Biofilms: implications in bioremediation. Trends Microbiol. 14, $389-397$. doi:10.1016/j.tim.2006.07.001

Van de Peer, Y., Chapelle, S., De Wachter, R., 1996. A quantitative map of nucleotide substitution rates in bacterial rRNA. Nucl Acids Res. 24, 3381-3391.

Velmurugan, N., Kalpana, D., Cho, J.-Y., Lee, G.-H., Park, S.-H., Lee, Y.-S., 2011. Phylogenetic analysis of culturable marine bacteria in sediments from South Korean Yellow Sea. Microbiology 80, 261-272. doi:10.1134/S0026261711010188

Yakimov, M.M., Timmis, K.N., Golyshin, P.N., 2007. Obligate oil-degrading marine bacteria. Curr. Opin. Biotechnol. 18, 257-66. doi:10.1016/j.copbio.2007.04.006 


\section{FIGURE CAPTIONS}

\section{Figure 1}

a) Location of the study area and sampling stations. Satellite image of Ancona harbor (Italy, Mediterranean Sea) showing the position of the sampling sites. b) Non-metric multidimensional scaling (nMDS) analysis based on ARISA fingerprinting showing the clustering of bacterial communities of sediment collected inside the harbour area (black triangles) and offshore (white squares). c) dbRDA ordinations of the ARISA dataset overlaid with the correlations of the tested environmental variables explaining the clustering of polluted and pristine sediment samples.

\section{Figure 2}

DGGE analysis of the bacterial communities in U5 and U7 sediments and the established enrichments. a) 16S rRNA DGGE of the enrichment cultures. b) Cluster analyses based on the 16S rRNA DGGE profiles. c) alkB-DGGE of the U5 and U7 sediments and established enrichments. The numbers indicate the cut bands (the results of $a l k B$ sequencing are reported in Table S2).

\section{Figure 3}

16S rRNA pyrosequencing of U5 and U7 sediments and U5 established enrichments. a) PCoA represents the structural diversity between bacterial communities. b) Summary of the number of reads, OTUs, singleton and coverage recorded for each sample. c) Relative abundance of the bacterial phylum detected through $16 \mathrm{~S}$ rRNA pyrosequencing. d) Relative abundance of the bacterial class detected through 16S rRNA pyrosequencing.

\section{Figure S1}

16S rRNA pyrosequencing of U5 and U7 sediments and U5 established enrichments. Relative abundance of the bacteria genera detected through $16 \mathrm{~S}$ rRNA pyrosequencing.

\section{Figure S2}

Rarefaction analysis of the 16S rRNA pyrosequencing libraries established from the total DNA extracted from U5 and U7 sediments and U5 enrichments. 


\section{TABLES}

\section{Table 1}

Physical characterization and value of total prokaryotic abundance of the surface sediments collected at the Ancona harbor.

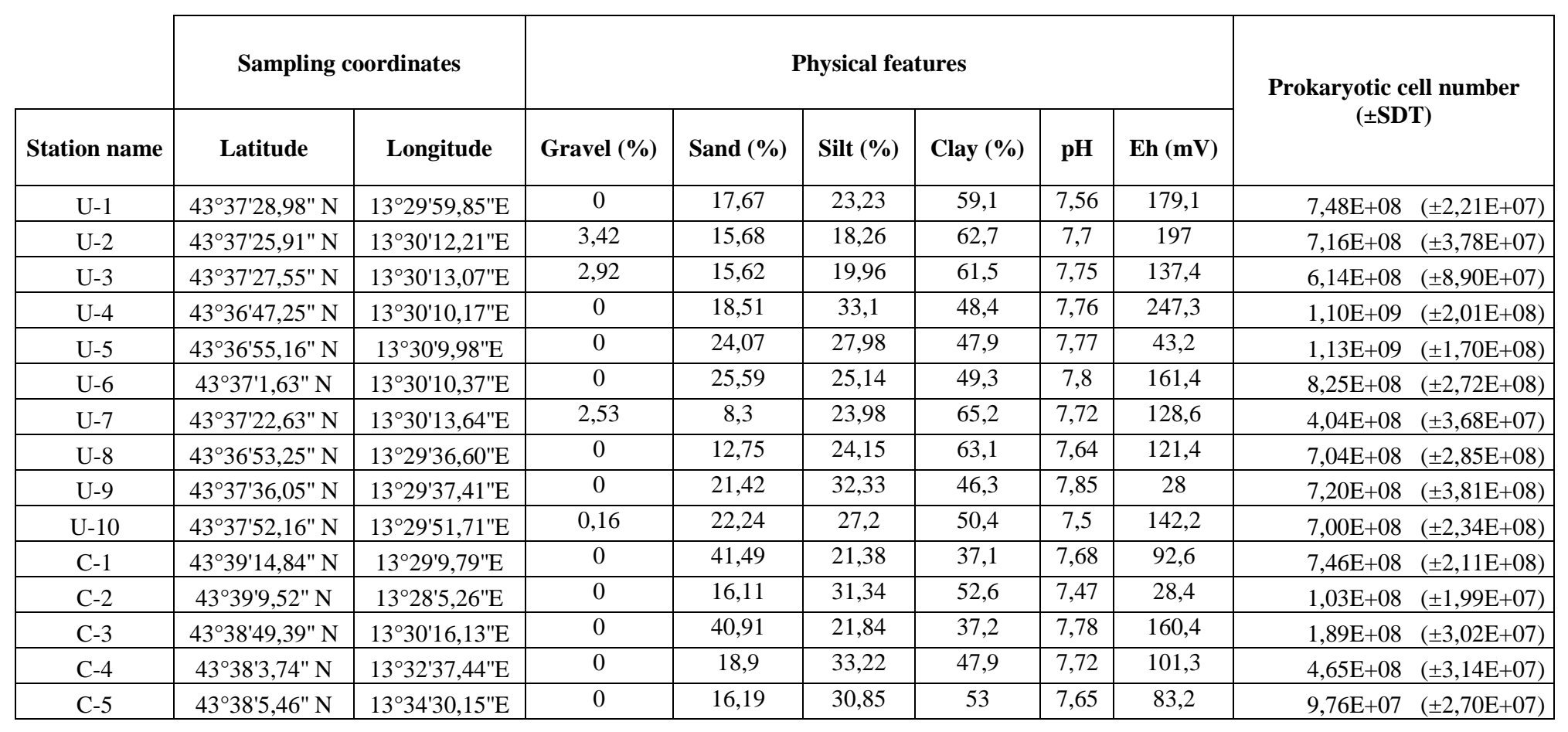




\section{Table 2}

Chemical composition (heavy metals, metalloids, hydrocarbons, TOC: Total Organic Carbon) of sediments collected at the Ancona harbor.

\begin{tabular}{|c|c|c|c|c|c|c|c|c|c|c|c|c|}
\hline \multirow[b]{2}{*}{$\begin{array}{c}\text { Station } \\
\text { name }\end{array}$} & \multicolumn{12}{|c|}{ Chemical characterization (mg/kg d.s) } \\
\hline & Hg & Cd & $\mathbf{P b}$ & As & $\mathrm{Cr}$ & $\mathbf{C u}$ & $\mathbf{N i}$ & $\mathbf{Z i}$ & $\mathbf{V}$ & HC: $\mathrm{C}>12$. & HC: Total PAH & TOC \\
\hline U-1 & 0,2 & 0,67 & 47,5 & 9,1 & 157,8 & 36,9 & 48,6 & 25 & 25 & 292 & 1,157 & 9,22 \\
\hline $\mathrm{U}-2$ & 0,1 & 0,8 & 18,9 & 6,2 & 517,3 & 39 & 61,6 & 107 & 60,3 & 252 & 0,359 & 8,58 \\
\hline $\mathrm{U}-3$ & 0,3 & 0,6 & 22,2 & 4,8 & 83,7 & 44 & 46,4 & 113,5 & 78,1 & 154 & 0,42 & 7,15 \\
\hline $\mathrm{U}-4$ & 0,05 & 0,6 & 15,1 & 5,5 & 105,1 & 23,9 & 52,9 & 88,9 & 73,4 & 65,3 & 3,697 & 9,8 \\
\hline U-5 & 0,1 & 0,58 & 11,7 & 6,8 & 429,2 & 32,2 & 63,8 & 93,4 & 56,7 & 152 & 0,03 & 9,42 \\
\hline U-6 & 0,1 & 0,57 & 12 & 6,2 & 130,6 & 32,3 & 52,1 & 89,9 & 57,7 & 165,6 & 0,087 & 9,63 \\
\hline U-7 & 0,3 & 0,8 & 9,1 & 8,5 & 107,6 & 57,6 & 191,1 & 148,6 & 93,7 & 316,5 & 0,358 & 7,26 \\
\hline U-8 & 0,1 & 0,56 & 25,5 & 7,9 & 88,4 & 28,7 & 47 & 106,5 & 62,4 & 152 & 0,487 & 8,23 \\
\hline U-9 & 0,1 & 0,6 & 16 & 7,5 & 137,3 & 34 & 55,9 & 89,3 & 66,5 & 106 & 0,164 & 7,99 \\
\hline U-10 & 0,1 & 0,6 & 17,4 & 8,2 & 84,4 & 23,7 & 54 & 86,6 & 51,8 & 119 & 0,584 & 8,32 \\
\hline C-1 & 0,05 & 0,29 & 7,2 & 6,7 & 72 & 22,4 & 42,2 & 47,9 & 40,7 & 2,5 & 0,008 & 7,84 \\
\hline $\mathrm{C}-2$ & 0,05 & 0,21 & 20,3 & 5 & 45,1 & 23,4 & 38,5 & 97,4 & 62,7 & 82,7 & 0,203 & 5,24 \\
\hline $\mathrm{C}-3$ & 0,05 & 0,25 & 10,7 & 7,7 & 44,6 & 20,3 & 47,9 & 63,9 & 40,2 & 11,9 & 0,047 & 6,03 \\
\hline C-4 & 0,1 & 0,24 & 10,2 & 7,8 & 89,2 & 18,7 & 48,9 & 66,7 & 57,8 & 19 & 0,106 & 7,01 \\
\hline C-5 & 0,05 & 0,28 & 18,5 & 6,2 & 46,3 & 28,8 & 46,7 & 99,1 & 50,8 & 58,8 & 0,182 & 5,05 \\
\hline
\end{tabular}




\section{Table 3}

Identification of the bacterial isolates (including the classification in ITS groups), and the results of the tested activities of potential interest for bioremediation.

\begin{tabular}{|c|c|c|c|c|c|c|c|c|c|}
\hline \multirow[b]{2}{*}{$\begin{array}{c}\text { ITS number } / \mathbf{N}^{\circ} \text { of } \\
\text { strains }\end{array}$} & \multirow[b]{2}{*}{ Closest described specie (ACC. $\mathbf{N}^{\circ}$ ) } & \multirow[b]{2}{*}{ Code } & \multirow[b]{2}{*}{ Drop collapse } & \multicolumn{3}{|c|}{ Emulsification } & \multirow[b]{2}{*}{$\begin{array}{l}\text { Biofilm formation } \\
\text { (adhesion unit) }\end{array}$} & \multirow[b]{2}{*}{$\begin{array}{l}\text { Uricolytic } \\
\text { activity }\end{array}$} & \multirow[b]{2}{*}{$\begin{array}{c}\text { Catechol } \\
\text { degradation }\end{array}$} \\
\hline & & & & EV 24 h & EV $48 \mathrm{~h}$ & Stability \% & & & \\
\hline \multirow{6}{*}{$(1 / 52)$} & Alcanivorax borkumensis (AB435569) & $\mathrm{U} 5-\mathrm{CO} 1$ & - & 11,6 & 10,5 & 90,5 & 3,15 & - & + \\
\hline & Alcanivorax borkumensis (AB435569) & $\mathrm{U} 5-\mathrm{CO} 3$ & - & 0,0 & 0,0 & na & 0,89 & - & + \\
\hline & Alcanivorax borkumensis (AB435569) & U5-CO11 & - & 0,0 & 0,0 & na & 0,75 & - & + \\
\hline & Alcanivorax borkumensis (AB435569) & U5-DB1 & - & 9,7 & 14,6 & 100,0 & 3,42 & - & + \\
\hline & Alcanivorax borkumensis (NR_074890) & U5-DS4 & - & 20,3 & 19,7 & 97,0 & 2,86 & - & + \\
\hline & Alcanivorax borkumensis (NR_074890) & U5-DS8 & - & 9,8 & 11,7 & 100,0 & 2,86 & - & + \\
\hline \multirow{2}{*}{$(3 / 3)$} & Alcanivorax borkumensis (NR_074890) & U5-DB11 & - & 40,5 & 26,9 & 66,4 & 3,32 & - & + \\
\hline & Alcanivorax borkumensis (NR_074890) & U5-DS9 & - & 5,2 & 6,1 & 100,0 & 2,91 & - & + \\
\hline \multirow{5}{*}{$(1 / 52)$} & Alcanivorax borkumensis (AB435569) & $\mathrm{U} 7-\mathrm{CO} 6$ & - & 20,1 & 15,8 & 78,6 & 0,96 & - & + \\
\hline & Alcanivorax borkumensis (AB435569) & $\mathrm{U} 7-\mathrm{CO} 14$ & - & 25,2 & 21,7 & 86,1 & 1,46 & 1,7 & + \\
\hline & Alcanivorax borkumensis (AB435569) & U7-DB18 & - & 33,3 & 32,2 & 96,7 & 0,15 & - & + \\
\hline & Alcanivorax borkumensis (AB435569) & U7-DS3 & - & 48,3 & 48,0 & 99,4 & 0,34 & - & + \\
\hline & Alcanivorax borkumensis (AB435569) & U7-DS10 & - & 36,4 & 35,6 & 97,8 & 0,24 & - & + \\
\hline$(7 / 1)$ & Marinobacter excellens (KC534446) & U7-DB8 & - & 29,4 & 27,9 & 94,9 & 1,44 & - & + \\
\hline$(2 / 1)$ & $\begin{array}{l}\text { Marinobacter hydrocarbonoclasticus } \\
\text { (NR_074619) }\end{array}$ & U5-DB8 & - & 0,0 & 0,0 & na & 3,17 & 1,8 & + \\
\hline$(4 / 1)$ & Marinobacter hydrocarbonoclasticus (JN160753) & U5-DB14 & - & 26,7 & 25,7 & 96,3 & 3,26 & 1,8 & + \\
\hline$(5 / 1)$ & Marinobacter hydrocarbonoclasticus (JQ799097) & U5-DB18 & - & 10,0 & 10,0 & 100,0 & 1,25 & 1,8 & + \\
\hline$(6 / 1)$ & Pseudomonas pachastrellae (AY880300) & U5-DS3 & - & 6,7 & 10,0 & 100,0 & 1,99 & - & + \\
\hline & & $\mathrm{CN}(\mathrm{ONR} 7 \mathrm{a})$ & - & 0,0 & 0,0 & na & 0 & - & - \\
\hline & & $\mathrm{CP}(\mathrm{SDS} 1 \%)$ & + & 62,0 & 60,8 & 98,1 & na & na & na \\
\hline
\end{tabular}




\section{Table S1}

Identification and relative abundance of the OTUs (97\% similarity) detected by 16S rRNA pyrosequencing in U5 and U7 sediments and U5 enrichment cultures.

\begin{tabular}{|c|c|c|c|c|c|c|c|c|c|c|}
\hline & phylum & class & order & family & genus & U5 & U7 & U5-DB & U5-CO & U5-N \\
\hline Bacteria & Uncl. Bacteria & Uncl. Bacteria & Uncl. Bacteria & Uncl. Bacteria & Uncl. Bacteria & 7,64973558 & 13,27566754 & 0,29459648 & 0,216727416 & 0,905947441 \\
\hline Bacteria & Acidobacteria & Uncl. Acidobacteria & Uncl. Acidobacteria & Uncl. Acidobacteria & Uncl. Acidobacteria & 0,036895831 & 0,131628432 & 0 & 0 & 0 \\
\hline Bacteria & Acidobacteria & AT-s2-57 & Uncl. Acidobacteria & Uncl. Acidobacteria & Uncl. Acidobacteria & 0 & 0,047010154 & 0 & 0 & 0 \\
\hline Bacteria & Acidobacteria & Acidobacteria-6 & BPC015 & Uncl. Acidobacteria & Uncl. Acidobacteria & 0 & 0,018804062 & 0 & 0 & 0 \\
\hline Bacteria & Acidobacteria & Acidobacteria-6 & CCU21 & Uncl. Acidobacteria & Uncl. Acidobacteria & 0,01229861 & 0,009402031 & 0 & 0 & 0 \\
\hline Bacteria & Acidobacteria & Acidobacteria-6 & iii1-15 & Uncl. Acidobacteria & Uncl. Acidobacteria & 0 & 0,018804062 & 0 & 0 & 0 \\
\hline Bacteria & Acidobacteria & Acidobacteriia & Acidobacteriales & Koribacteraceae & Uncl. Koribacteraceae & 0 & 0,009402031 & 0 & 0 & 0 \\
\hline Bacteria & Acidobacteria & BPC102 & B110 & Uncl. Acidobacteria & Uncl. Acidobacteria & 0,381256918 & 0,253854833 & 0 & 0 & 0 \\
\hline Bacteria & Acidobacteria & BPC102 & MVS-40 & Uncl. Acidobacteria & Uncl. Acidobacteria & 0 & 0,018804062 & 0 & 0 & 0 \\
\hline Bacteria & Acidobacteria & OS-K & Uncl. Acidobacteria & Uncl. Acidobacteria & Uncl. Acidobacteria & 1,488131841 & 0,545317789 & 0 & 0 & 0 \\
\hline Bacteria & Acidobacteria & RB25 & Uncl. Acidobacteria & Uncl. Acidobacteria & Uncl. Acidobacteria & 0,196777764 & 0,11282437 & 0 & 0 & 0 \\
\hline Bacteria & Acidobacteria & Sva0725 & Sva0725 & Uncl. Acidobacteria & Uncl. Acidobacteria & 0,221374985 & 0,244452802 & 0 & 0 & 0,006915629 \\
\hline Bacteria & Acidobacteria & iii1-8 & $32-20$ & Uncl. Acidobacteria & Uncl. Acidobacteria & 0 & 0,009402031 & 0 & 0 & 0 \\
\hline Bacteria & Actinobacteria & Uncl. Actinobacteria & Uncl. Actinobacteria & Uncl. Actinobacteria & Uncl. Actinobacteria & 0,01229861 & 0 & 0 & 0 & 0 \\
\hline Bacteria & Actinobacteria & Acidimicrobiia & Acidimicrobiales & Uncl. Acidimicrobiales & Uncl. Acidimicrobiales & 0 & 0,037608123 & 0 & 0 & 0 \\
\hline Bacteria & Actinobacteria & Acidimicrobiia & Acidimicrobiales & Uncl. Acidimicrobiales & Uncl. Acidimicrobiales & 0 & 0,028206093 & 0 & 0 & 0 \\
\hline Bacteria & Actinobacteria & Acidimicrobiia & Acidimicrobiales & C111 & Uncl. Acidimicrobiales & 0 & 0,056412185 & 0 & 0 & 0,006915629 \\
\hline Bacteria & Actinobacteria & Acidimicrobiia & Acidimicrobiales & EB1017 & Uncl. Acidimicrobiales & 0 & 0,018804062 & 0 & 0 & 0 \\
\hline Bacteria & Actinobacteria & Acidimicrobiia & Acidimicrobiales & koll13 & Uncl. Acidimicrobiales & 0,172180544 & 0,347875141 & 0 & 0 & 0,020746888 \\
\hline Bacteria & Actinobacteria & Actinobacteria & Actinomycetales & Uncl. Actinomycetales & Uncl. Actinomycetales & 0 & 0,009402031 & 0 & 0 & 0 \\
\hline Bacteria & Actinobacteria & Actinobacteria & Actinomycetales & Bogoriellaceae & Georgenia & 0 & 0,037608123 & 0 & 0 & 0 \\
\hline Bacteria & Actinobacteria & Actinobacteria & Actinomycetales & Geodermatophilaceae & Geodermatophilus & 0 & 0,009402031 & 0 & 0 & 0 \\
\hline Bacteria & Actinobacteria & Actinobacteria & Actinomycetales & Intrasporangiaceae & Other & 0 & 0,018804062 & 0 & 0 & 0 \\
\hline Bacteria & Actinobacteria & Actinobacteria & Actinomycetales & Microbacteriaceae & Uncl. Microbacteriaceae & 0 & 0,018804062 & 0 & 0 & 0 \\
\hline Bacteria & Actinobacteria & Actinobacteria & Actinomycetales & Microbacteriaceae & Agrococcus & 0 & 0 & 0 & 0 & 0,006915629 \\
\hline Bacteria & Actinobacteria & Actinobacteria & Actinomycetales & Microbacteriaceae & Microbacterium & 0 & 0,009402031 & 0 & 0 & 0 \\
\hline
\end{tabular}




\begin{tabular}{|c|c|c|c|c|c|c|c|c|c|c|}
\hline & phylum & class & order & family & genus & U5 & U7 & U5-DB & U5-CO & U5-N \\
\hline Bacteria & Actinobacteria & Actinobacteria & Actinomycetales & Mycobacteriaceae & Mycobacterium & 0 & 0,009402031 & 0 & 0 & 0 \\
\hline Bacteria & Actinobacteria & Actinobacteria & Actinomycetales & Pseudonocardiaceae & Uncl. Pseudonocardiaceae & 0 & 0,018804062 & 0 & 0 & 0 \\
\hline Bacteria & Actinobacteria & Actinobacteria & WCHB1-81 & At425_EubF1 & Uncl. Actinobacteria & 0 & 0,009402031 & 0 & 0 & 0 \\
\hline Bacteria & Actinobacteria & OPB41 & Uncl. Actinobacteria & Uncl. Actinobacteria & Uncl. Actinobacteria & 0,024597221 & 0,065814216 & 0 & 0 & 0 \\
\hline Bacteria & Actinobacteria & Thermoleophilia & Uncl. Thermoleophilia & Uncl. Thermoleophilia & Uncl. Thermoleophilia & 0,024597221 & 0 & 0 & 0 & 0 \\
\hline Bacteria & Actinobacteria & Thermoleophilia & Gaiellales & Gaiellaceae & Uncl. Gaiellaceae & 0 & 0,122226401 & 0 & 0 & 0 \\
\hline Bacteria & Actinobacteria & Thermoleophilia & Solirubrobacterales & Other & Other & 0 & 0,009402031 & 0 & 0 & 0 \\
\hline Bacteria & Actinobacteria & Thermoleophilia & Solirubrobacterales & Uncl. Solirubrobacterales & Uncl. Solirubrobacterales & 0 & 0,018804062 & 0 & 0 & 0 \\
\hline Bacteria & Actinobacteria & Thermoleophilia & Solirubrobacterales & Solirubrobacteraceae & Uncl. Solirubrobacteraceae & 0 & 0,009402031 & 0 & 0 & 0 \\
\hline Bacteria & $\mathrm{BRC} 1$ & NPL-UPA2 & Uncl. Bacteria & Uncl. Bacteria & Uncl. Bacteria & 0,01229861 & 0,018804062 & 0 & 0 & 0 \\
\hline Bacteria & Bacteroidetes & Bacteroidia & Bacteroidales & Other & Other & 0,01229861 & 0 & 0 & 0 & 0 \\
\hline Bacteria & Bacteroidetes & Bacteroidia & Bacteroidales & Uncl. Bacteroidales & Uncl. Bacteroidales & 2,533513713 & 2,265889432 & 0 & 0 & 0,062240664 \\
\hline Bacteria & Bacteroidetes & Bacteroidia & Bacteroidales & Marinilabiaceae & Uncl. Marinilabiaceae & 0,01229861 & 0,028206093 & 0 & 0 & 0 \\
\hline Bacteria & Bacteroidetes & Bacteroidia & Bacteroidales & SB-1 & Uncl. Bacteroidales & 0,122986103 & 0,178638586 & 0 & 0 & 0 \\
\hline Bacteria & Bacteroidetes & Bacteroidia & Bacteroidales & VC21_Bac22 & Uncl. Bacteroidales & 0,553437462 & 0,169236555 & 0 & 0 & 0,062240664 \\
\hline Bacteria & Bacteroidetes & Cytophagia & Cytophagales & Cytophagaceae & Uncl. Cytophagaceae & 0 & 0,009402031 & 0 & 0 & 0 \\
\hline Bacteria & Bacteroidetes & Cytophagia & Cytophagales & Flammeovirgaceae & Uncl. Flammeovirgaceae & 0,135284713 & 0,197442648 & 0 & 0 & 0 \\
\hline Bacteria & Bacteroidetes & Flavobacteriia & Flavobacteriales & Cryomorphaceae & Fluviicola & 0,01229861 & 0,009402031 & 0 & 0 & 0 \\
\hline Bacteria & Bacteroidetes & Flavobacteriia & Flavobacteriales & Flavobacteriaceae & Other & 0,061493051 & 0,178638586 & 0 & 0 & 0 \\
\hline Bacteria & Bacteroidetes & Flavobacteriia & Flavobacteriales & Flavobacteriaceae & Uncl. Flavobacteriaceae & 5,768048211 & 5,998495675 & 1,302426545 & 0,866909664 & 0,096818811 \\
\hline Bacteria & Bacteroidetes & Flavobacteriia & Flavobacteriales & Flavobacteriaceae & Aequorivita & 0 & 0 & 0 & 0,088661216 & 0 \\
\hline Bacteria & Bacteroidetes & Flavobacteriia & Flavobacteriales & Flavobacteriaceae & Bizionia & 0 & 0,037608123 & 0,007752539 & 0,049256231 & 0 \\
\hline Bacteria & Bacteroidetes & Flavobacteriia & Flavobacteriales & Flavobacteriaceae & Flavobacterium & 0 & 0,037608123 & 0 & 0 & 0 \\
\hline Bacteria & Bacteroidetes & Flavobacteriia & Flavobacteriales & Flavobacteriaceae & Lutimonas & 0,01229861 & 0,009402031 & 0 & 0 & 0 \\
\hline Bacteria & Bacteroidetes & Flavobacteriia & Flavobacteriales & Flavobacteriaceae & Psychroflexus & 0 & 0,009402031 & 0 & 0 & 0 \\
\hline Bacteria & Bacteroidetes & Flavobacteriia & Flavobacteriales & Flavobacteriaceae & Robiginitalea & 0,147583323 & 0,197442648 & 0 & 0 & 0 \\
\hline Bacteria & Bacteroidetes & Flavobacteriia & Flavobacteriales & Flavobacteriaceae & Sediminicola & 0 & 0,056412185 & 0 & 0 & 0 \\
\hline Bacteria & Bacteroidetes & Flavobacteriia & Flavobacteriales & Flavobacteriaceae & Tenacibaculum & 0 & 0,009402031 & 0 & 0,147768693 & 0 \\
\hline Bacteria & Bacteroidetes & Flavobacteriia & Flavobacteriales & Flavobacteriaceae & Ulvibacter & 0,01229861 & 0,197442648 & 0 & 0 & 0 \\
\hline Bacteria & Bacteroidetes & Flavobacteriia & Flavobacteriales & Flavobacteriaceae & Winogradskyella & 0,01229861 & 0,037608123 & 0 & 0 & 0 \\
\hline
\end{tabular}




\begin{tabular}{|c|c|c|c|c|c|c|c|c|c|c|}
\hline & phylum & class & order & family & genus & U5 & U7 & U5-DB & U5-CO & U5-N \\
\hline Bacteria & Bacteroidetes & [Rhodothermi] & [Rhodothermales] & Rhodothermaceae & Uncl. Rhodothermaceae & 0 & 0,018804062 & 0 & 0 & 0 \\
\hline Bacteria & Bacteroidetes & [Saprospirae] & [Saprospirales] & Chitinophagaceae & Uncl. Chitinophagaceae & 0 & 0,028206093 & 0 & 0 & 0 \\
\hline Bacteria & Caldithrix & Caldithrixae & Caldithrixales & Caldithrixaceae & Uncl. Caldithrixaceae & 0,036895831 & 0,018804062 & 0 & 0 & 0 \\
\hline Bacteria & Caldithrix & Caldithrixae & Caldithrixales & Caldithrixaceae & LCP-26 & 0,061493051 & 0,056412185 & 0 & 0 & 0 \\
\hline Bacteria & Chlorobi & Uncl. Chlorobi & Uncl. Chlorobi & Uncl. Chlorobi & Uncl. Chlorobi & 0 & 0 & 0 & 0 & 0,013831259 \\
\hline Bacteria & Chlorobi & BSV26 & PK329 & Uncl. Chlorobi & Uncl. Chlorobi & 0 & 0,037608123 & 0 & 0 & 0 \\
\hline Bacteria & Chlorobi & Ignavibacteria & Ignavibacteriales & Ignavibacteriaceae & Uncl. Ignavibacteriaceae & 0,01229861 & 0,028206093 & 0 & 0 & 0 \\
\hline Bacteria & Chlorobi & Ignavibacteria & Ignavibacteriales & lheB3-7 & Uncl. Ignavibacteriales & 0,159881933 & 0,065814216 & 0 & 0 & 0,006915629 \\
\hline Bacteria & Chlorobi & OPB56 & Uncl. Chlorobi & Uncl. Chlorobi & Uncl. Chlorobi & 0,01229861 & 0 & 0 & 0 & 0 \\
\hline Bacteria & Chloroflexi & Anaerolineae & Uncl. Anaerolineae & Uncl. Anaerolineae & Uncl. Anaerolineae & 0,024597221 & 0 & 0 & 0 & 0 \\
\hline Bacteria & Chloroflexi & Anaerolineae & Anaerolineales & Anaerolinaceae & C1_B004 & 0,049194441 & 0,056412185 & 0 & 0 & 0 \\
\hline Bacteria & Chloroflexi & Anaerolineae & Anaerolineales & Anaerolinaceae & $\mathrm{T} 78$ & 0,270569426 & 0,065814216 & 0 & 0 & 0 \\
\hline Bacteria & Chloroflexi & Anaerolineae & Caldilineales & Caldilineaceae & Caldilinea & 0 & 0,009402031 & 0 & 0 & 0 \\
\hline Bacteria & Chloroflexi & Anaerolineae & DRC31 & Uncl. Anaerolineae & Uncl. Anaerolineae & 0,098388882 & 0 & 0 & 0 & 0 \\
\hline Bacteria & Chloroflexi & Anaerolineae & GCA004 & Uncl. Anaerolineae & Uncl. Anaerolineae & 0,4796458 & 0,366679203 & 0 & 0 & 0 \\
\hline Bacteria & Chloroflexi & Anaerolineae & MSB-1E9 & Uncl. Anaerolineae & Uncl. Anaerolineae & 0,024597221 & 0 & 0 & 0 & 0 \\
\hline Bacteria & Chloroflexi & Anaerolineae & O4D2Z37 & Uncl. Anaerolineae & Uncl. Anaerolineae & 0,110687492 & 0,009402031 & 0 & 0 & 0 \\
\hline Bacteria & Chloroflexi & Anaerolineae & OPB11 & Uncl. Anaerolineae & Uncl. Anaerolineae & 0 & 0,018804062 & 0 & 0 & 0 \\
\hline Bacteria & Chloroflexi & Anaerolineae & S0208 & Uncl. Anaerolineae & Uncl. Anaerolineae & 0,01229861 & 0 & 0 & 0 & 0 \\
\hline Bacteria & Chloroflexi & Anaerolineae & SB-34 & Uncl. Anaerolineae & Uncl. Anaerolineae & 0,024597221 & 0,131628432 & 0 & 0 & 0 \\
\hline Bacteria & Chloroflexi & Anaerolineae & SBR1031 & SHA-31 & Uncl. Anaerolineae & 0 & 0,009402031 & 0 & 0 & 0 \\
\hline Bacteria & Chloroflexi & Anaerolineae & SHA-20 & Uncl. Anaerolineae & Uncl. Anaerolineae & 0,01229861 & 0,018804062 & 0 & 0 & 0 \\
\hline Bacteria & Chloroflexi & Dehalococcoidetes & Uncl. Dehalococcoidetes & Uncl. Dehalococcoidetes & Uncl. Dehalococcoidetes & 0,073791662 & 0,188040617 & 0 & 0 & 0 \\
\hline Bacteria & Chloroflexi & Dehalococcoidetes & Dehalococcoidales & Dehalococcoidaceae & Uncl. Dehalococcoidaceae & 0,061493051 & 0 & 0 & 0 & 0,006915629 \\
\hline Bacteria & Chloroflexi & Dehalococcoidetes & \begin{tabular}{|l|} 
FS117-23B-02 \\
\end{tabular} & Uncl. Dehalococcoidetes & Uncl. Dehalococcoidetes & 0 & 0,037608123 & 0 & 0 & 0 \\
\hline Bacteria & Chloroflexi & Ellin6529 & Uncl. Chloroflexi & Uncl. Chloroflexi & Uncl. Chloroflexi & 0,01229861 & 0,22564874 & 0 & 0 & 0,027662517 \\
\hline Bacteria & Chloroflexi & Thermomicrobia & JG30-KF-CM45 & Uncl. Thermomicrobia & Uncl. Thermomicrobia & 0 & 0,018804062 & 0 & 0 & 0 \\
\hline
\end{tabular}




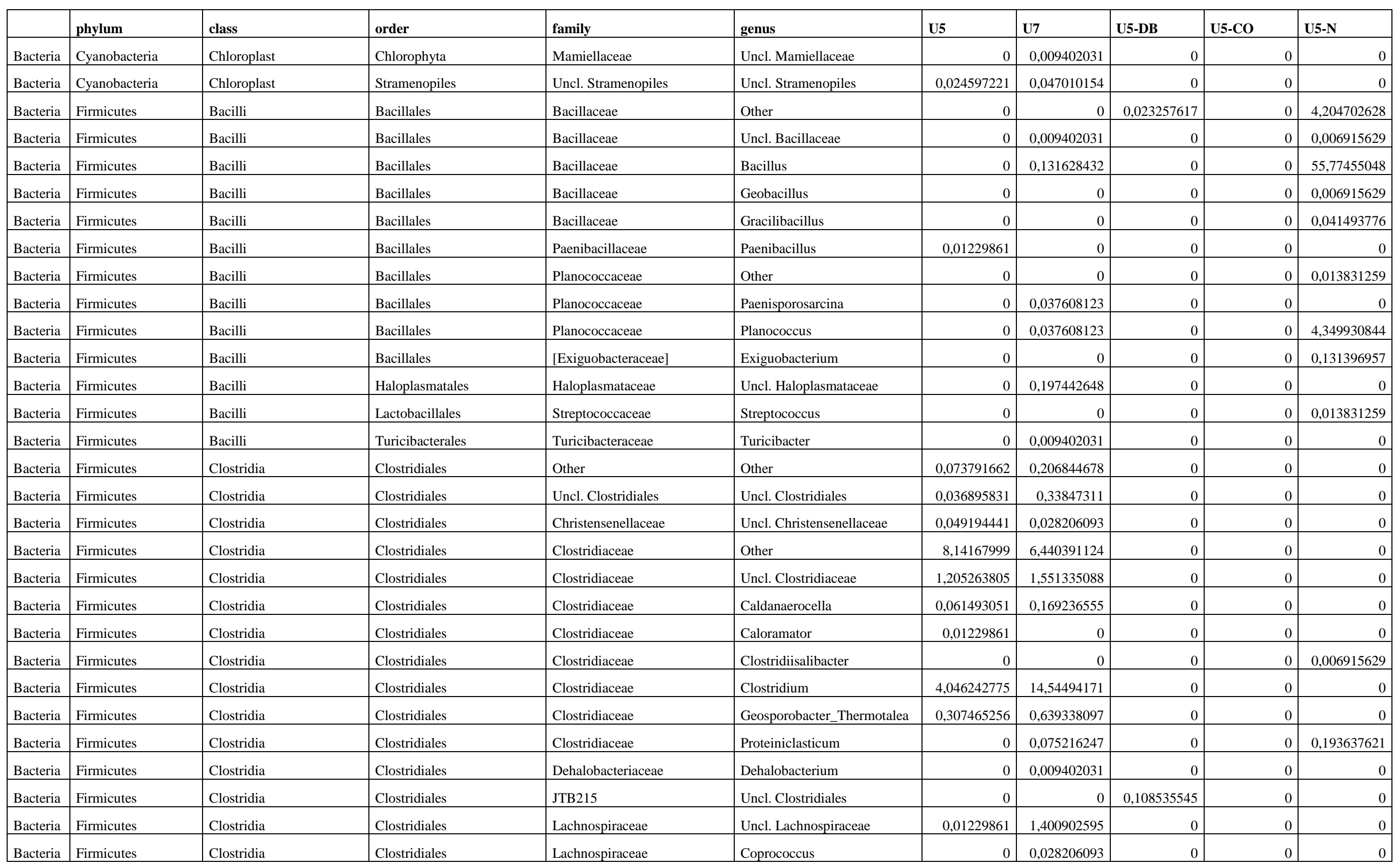




\begin{tabular}{|c|c|c|c|c|c|c|c|c|c|c|}
\hline & phylum & class & order & family & genus & U5 & U7 & U5-DB & U5-CO & U5-N \\
\hline Bacteria & Firmicutes & Clostridia & Clostridiales & Peptococcaceae & Desulfonispora & 0 & 0,009402031 & 0 & 0 & 0 \\
\hline Bacteria & Firmicutes & Clostridia & Clostridiales & Peptostreptococcaceae & Uncl. Peptostreptococcaceae & 0 & 0,009402031 & 0 & 0 & 0 \\
\hline Bacteria & Firmicutes & Clostridia & Clostridiales & Ruminococcaceae & Uncl. Ruminococcaceae & 0,086090272 & 0,065814216 & 0 & 0 & 0 \\
\hline Bacteria & Firmicutes & Clostridia & Clostridiales & Ruminococcaceae & Oscillospira & 0,01229861 & 0,009402031 & 0 & 0 & 0 \\
\hline Bacteria & Firmicutes & Clostridia & Clostridiales & [Acidaminobacteraceae] & Uncl. Clostridiales & 0,45504858 & 2,999247838 & 0 & 0 & 0 \\
\hline Bacteria & Firmicutes & Clostridia & Clostridiales & [Acidaminobacteraceae] & Fusibacter & 0,147583323 & 0,291462956 & 0,015505078 & 0 & 0 \\
\hline Bacteria & Firmicutes & Clostridia & Clostridiales & [Acidaminobacteraceae] & WH1-8 & 1,094576313 & 1,664159458 & 0 & 0 & 0,193637621 \\
\hline Bacteria & Firmicutes & Clostridia & Clostridiales & [Mogibacteriaceae] & Other & 0,01229861 & 0 & 0 & 0 & 0 \\
\hline Bacteria & Firmicutes & Clostridia & Clostridiales & [Mogibacteriaceae] & Uncl. Clostridiales & 0 & 0,009402031 & 0 & 0 & 0 \\
\hline Bacteria & Firmicutes & Clostridia & Clostridiales & [Mogibacteriaceae] & Anaerovorax & 0,01229861 & 0,065814216 & 0 & 0 & 0 \\
\hline Bacteria & Firmicutes & Clostridia & Clostridiales & [Tissierellaceae] & Dethiosulfatibacter & 0,036895831 & 0 & 0 & 0 & 0 \\
\hline Bacteria & Firmicutes & Clostridia & Clostridiales & [Tissierellaceae] & Sedimentibacter & 0,036895831 & 0 & 0 & 0 & 0 \\
\hline Bacteria & GN02 & $3 \mathrm{BR}-5 \mathrm{~F}$ & Uncl. Bacteria & Uncl. Bacteria & Uncl. Bacteria & 0,049194441 & 0,159834524 & 0 & 0 & 0 \\
\hline Bacteria & GN02 & BB34 & Uncl. Bacteria & Uncl. Bacteria & Uncl. Bacteria & 0,159881933 & 0,075216247 & 0 & 0 & 0 \\
\hline Bacteria & GNO2 & GN10 & Uncl. Bacteria & Uncl. Bacteria & Uncl. Bacteria & 0,024597221 & 0 & 0 & 0 & 0 \\
\hline Bacteria & GN04 & Uncl. Bacteria & Uncl. Bacteria & Uncl. Bacteria & Uncl. Bacteria & 0 & 0,037608123 & 0 & 0 & 0 \\
\hline Bacteria & GN04 & GN15 & Uncl. Bacteria & Uncl. Bacteria & Uncl. Bacteria & 0,578034682 & 0,150432493 & 0 & 0 & 0 \\
\hline Bacteria & Gemmatimonadetes & Uncl. Gemmatimonadetes & Uncl. Gemmatimonadetes & Uncl. Gemmatimonadetes & Uncl. Gemmatimonadetes & 0 & 0,009402031 & 0 & 0 & 0 \\
\hline Bacteria & Gemmatimonadetes & Gemm-1 & Uncl. Gemmatimonadetes & Uncl. Gemmatimonadetes & Uncl. Gemmatimonadetes & 0 & 0,047010154 & 0 & 0 & 0 \\
\hline Bacteria & Gemmatimonadetes & Gemm-2 & Uncl. Gemmatimonadetes & Uncl. Gemmatimonadetes & Uncl. Gemmatimonadetes & 0,01229861 & 0,028206093 & 0 & 0 & 0 \\
\hline Bacteria & Gemmatimonadetes & Gemm-4 & Uncl. Gemmatimonadetes & Uncl. Gemmatimonadetes & Uncl. Gemmatimonadetes & 0,110687492 & 0,244452802 & 0 & 0 & 0,006915629 \\
\hline Bacteria & Gemmatimonadetes & Gemmatimonadetes & Uncl. Gemmatimonadetes & Uncl. Gemmatimonadetes & Uncl. Gemmatimonadetes & 0 & 0,065814216 & 0 & 0 & 0 \\
\hline Bacteria & Gemmatimonadetes & JL-ETNP-Z39 & Uncl. Gemmatimonadetes & Uncl. Gemmatimonadetes & Uncl. Gemmatimonadetes & 0,01229861 & 0 & 0 & 0 & 0 \\
\hline Bacteria & Hyd24-12 & WM88 & Uncl. Bacteria & Uncl. Bacteria & Uncl. Bacteria & 0,086090272 & 0,028206093 & 0 & 0 & 0 \\
\hline Bacteria & Lentisphaerae & [Lentisphaeria] & $\mathrm{Z} 20$ & Uncl. Z20 & Uncl. Z20 & 0 & 0,018804062 & 0 & 0 & 0 \\
\hline Bacteria & Nitrospirae & Nitrospira & Nitrospirales & [Thermodesulfovibrionaceae] & LCP-6 & 0 & 0,056412185 & 0 & 0 & 0 \\
\hline Bacteria & OD1 & Uncl. Bacteria & Uncl. Bacteria & Uncl. Bacteria & Uncl. Bacteria & 0,01229861 & 0 & 0 & 0 & 0,013831259 \\
\hline
\end{tabular}




\begin{tabular}{|c|c|c|c|c|c|c|c|c|c|c|}
\hline & phylum & class & order & family & genus & U5 & U7 & U5-DB & U5-CO & U5-N \\
\hline Bacteria & OD1 & ABY1 & Uncl. Bacteria & Uncl. Bacteria & Uncl. Bacteria & 0,135284713 & 0,028206093 & 0 & 0 & 0 \\
\hline Bacteria & OP11 & OP11-3 & Uncl. Bacteria & Uncl. Bacteria & Uncl. Bacteria & 0 & 0,009402031 & 0 & 0 & 0 \\
\hline Bacteria & OP3 & koll11 & Uncl. Bacteria & Uncl. Bacteria & Uncl. Bacteria & 0 & 0,018804062 & 0 & 0 & 0 \\
\hline Bacteria & OP8 & OP8_1 & HMMVPog-54 & Uncl. Bacteria & Uncl. Bacteria & 0,061493051 & 0,075216247 & 0 & 0 & 0 \\
\hline Bacteria & OP8 & OP8_2 & Uncl. Bacteria & Uncl. Bacteria & Uncl. Bacteria & 0 & 0,047010154 & 0 & 0 & 0 \\
\hline Bacteria & OP8 & SAW1_B6 & Uncl. Bacteria & Uncl. Bacteria & Uncl. Bacteria & 0,122986103 & 0,300864987 & 0 & 0 & 0 \\
\hline Bacteria & OP9 & JS1 & SB-45 & Uncl. Bacteria & Uncl. Bacteria & 0,024597221 & 0 & 0 & 0 & 0 \\
\hline Bacteria & Planctomycetes & Uncl. Planctomycetes & Uncl. Planctomycetes & Uncl. Planctomycetes & Uncl. Planctomycetes & 0,024597221 & 0,018804062 & 0 & 0 & 0 \\
\hline Bacteria & Planctomycetes & 028H05-P-BN-P5 & Uncl. Planctomycetes & Uncl. Planctomycetes & Uncl. Planctomycetes & 0 & 0,009402031 & 0 & 0 & 0 \\
\hline Bacteria & Planctomycetes & C6 & Ucm1571 & Uncl. Planctomycetes & Uncl. Planctomycetes & 0 & 0,018804062 & 0 & 0 & 0 \\
\hline Bacteria & Planctomycetes & C6 & d113 & Uncl. Planctomycetes & Uncl. Planctomycetes & 0,01229861 & 0 & 0 & 0 & 0 \\
\hline Bacteria & Planctomycetes & OM190 & $\operatorname{agg} 27$ & Uncl. Planctomycetes & Uncl. Planctomycetes & 0 & 0,009402031 & 0 & 0 & 0 \\
\hline Bacteria & Planctomycetes & Phycisphaerae & C86 & Uncl. Phycisphaerae & Uncl. Phycisphaerae & 0 & 0,037608123 & 0 & 0 & 0 \\
\hline Bacteria & Planctomycetes & Phycisphaerae & CCM11a & Uncl. Phycisphaerae & Uncl. Phycisphaerae & 0 & 0,009402031 & 0 & 0 & 0 \\
\hline Bacteria & Planctomycetes & Phycisphaerae & MSBL9 & Uncl. Phycisphaerae & Uncl. Phycisphaerae & 0,147583323 & 0,131628432 & 0 & 0 & 0,020746888 \\
\hline Bacteria & Planctomycetes & Phycisphaerae & Phycisphaerales & Uncl. Phycisphaerales & Uncl. Phycisphaerales & 0,049194441 & 0,018804062 & 0 & 0 & 0 \\
\hline Bacteria & Planctomycetes & Phycisphaerae & Pla1 & Uncl. Phycisphaerae & Uncl. Phycisphaerae & 0 & 0,009402031 & 0 & 0 & 0 \\
\hline Bacteria & Planctomycetes & Phycisphaerae & SHA-43 & Uncl. Phycisphaerae & Uncl. Phycisphaerae & 0 & 0,028206093 & 0 & 0 & 0 \\
\hline Bacteria & Planctomycetes & Phycisphaerae & WD2101 & Uncl. Phycisphaerae & Uncl. Phycisphaerae & 0 & 0,009402031 & 0 & 0 & 0 \\
\hline Bacteria & Planctomycetes & Phycisphaerae & mle1-8 & Uncl. Phycisphaerae & Uncl. Phycisphaerae & 0,098388882 & 0,028206093 & 0 & 0 & 0 \\
\hline Bacteria & Planctomycetes & Pla3 & Uncl. Planctomycetes & Uncl. Planctomycetes & Uncl. Planctomycetes & 0,01229861 & 0 & 0 & 0 & 0 \\
\hline Bacteria & Planctomycetes & Planctomycetia & Pirellulales & Pirellulaceae & Uncl. Pirellulaceae & 0,135284713 & 0,404287326 & 0 & 0 & 0,006915629 \\
\hline Bacteria & Planctomycetes & Planctomycetia & Pirellulales & Pirellulaceae & A17 & 0 & 0 & 0 & 0 & 0,006915629 \\
\hline Bacteria & Planctomycetes & Planctomycetia & Planctomycetales & Planctomycetaceae & Planctomyces & 0 & 0,009402031 & 0 & 0 & 0 \\
\hline Bacteria & Proteobacteria & Other & Other & Other & Other & 0 & 0,009402031 & 0 & 0 & 0 \\
\hline Bacteria & Proteobacteria & Alphaproteobacteria & Rhizobiales & Other & Other & 0 & 0,018804062 & 0 & 0 & 0 \\
\hline Bacteria & Proteobacteria & Alphaproteobacteria & Rhizobiales & Uncl. Rhizobiales & Uncl. Rhizobiales & 0 & 0,075216247 & 0 & 0 & 0 \\
\hline
\end{tabular}




\begin{tabular}{|c|c|c|c|c|c|c|c|c|c|c|}
\hline & phylum & class & order & family & genus & U5 & U7 & U5-DB & U5-CO & U5-N \\
\hline Bacteria & Proteobacteria & Alphaproteobacteria & Rhizobiales & Beijerinckiaceae & Uncl. Beijerinckiaceae & 0 & 0,009402031 & 0 & 0 & 0 \\
\hline Bacteria & Proteobacteria & Alphaproteobacteria & Rhizobiales & Bradyrhizobiaceae & Balneimonas & 0 & 0,037608123 & 0 & 0 & 0 \\
\hline Bacteria & Proteobacteria & Alphaproteobacteria & Rhizobiales & Hyphomicrobiaceae & Uncl. Hyphomicrobiaceae & 0,036895831 & 0,319669049 & 0 & 0 & 0 \\
\hline Bacteria & Proteobacteria & Alphaproteobacteria & Rhizobiales & Hyphomicrobiaceae & Devosia & 0 & 0,009402031 & 0 & 0 & 0 \\
\hline Bacteria & Proteobacteria & Alphaproteobacteria & Rhizobiales & Hyphomicrobiaceae & Hyphomicrobium & 0,061493051 & 0,028206093 & 0 & 0 & 0 \\
\hline Bacteria & Proteobacteria & Alphaproteobacteria & Rhizobiales & Hyphomicrobiaceae & Pedomicrobium & 0 & 0,094020308 & 0 & 0 & 0 \\
\hline Bacteria & Proteobacteria & Alphaproteobacteria & Rhizobiales & Hyphomicrobiaceae & Rhodoplanes & 0 & 0,047010154 & 0 & 0 & 0,013831259 \\
\hline Bacteria & Proteobacteria & Alphaproteobacteria & Rhizobiales & Methylobacteriaceae & Uncl. Methylobacteriaceae & 0,01229861 & 0 & 0 & 0 & 0 \\
\hline Bacteria & Proteobacteria & Alphaproteobacteria & Rhizobiales & Phyllobacteriaceae & Uncl. Phyllobacteriaceae & 0 & 0,150432493 & 0 & 0 & 0 \\
\hline Bacteria & Proteobacteria & Alphaproteobacteria & Rhizobiales & Rhodobiaceae & Afifella & 0 & 0,009402031 & 0 & 0 & 0 \\
\hline Bacteria & Proteobacteria & Alphaproteobacteria & Rhizobiales & Xanthobacteraceae & Uncl. Xanthobacteraceae & 0 & 0,009402031 & 0 & 0 & 0 \\
\hline Bacteria & Proteobacteria & Alphaproteobacteria & Rhodobacterales & Hyphomonadaceae & Uncl. Hyphomonadaceae & 0 & 0,009402031 & 0 & 0 & 0 \\
\hline Bacteria & Proteobacteria & Alphaproteobacteria & Rhodobacterales & Rhodobacteraceae & Other & 0,172180544 & 0,432493419 & 0,046515234 & 4,561126983 & 0,027662517 \\
\hline Bacteria & Proteobacteria & Alphaproteobacteria & Rhodobacterales & Rhodobacteraceae & Uncl. Rhodobacteraceae & 0,233673595 & 2,106054908 & 0,031010156 & 0,374347355 & 0,020746888 \\
\hline Bacteria & Proteobacteria & Alphaproteobacteria & Rhodobacterales & Rhodobacteraceae & Anaerospora & 0,098388882 & 0 & 0 & 0,029553739 & 0 \\
\hline Bacteria & Proteobacteria & Alphaproteobacteria & Rhodobacterales & Rhodobacteraceae & Dinoroseobacter & 0 & 0,018804062 & 0 & 0 & 0 \\
\hline Bacteria & Proteobacteria & Alphaproteobacteria & Rhodobacterales & Rhodobacteraceae & Loktanella & 0,024597221 & 0,723956375 & 0 & 0 & 0 \\
\hline Bacteria & Proteobacteria & Alphaproteobacteria & Rhodobacterales & Rhodobacteraceae & Marivita & 0 & 0,009402031 & 0 & 0 & 0 \\
\hline Bacteria & Proteobacteria & Alphaproteobacteria & Rhodobacterales & Rhodobacteraceae & Octadecabacter & 0,073791662 & 0,460699511 & 0 & 0 & 0 \\
\hline Bacteria & Proteobacteria & Alphaproteobacteria & Rhodobacterales & Rhodobacteraceae & Phaeobacter & 0,024597221 & 0,122226401 & 0 & 0,039404985 & 0 \\
\hline Bacteria & Proteobacteria & Alphaproteobacteria & Rhodobacterales & Rhodobacteraceae & Pseudoruegeria & 0 & 0,018804062 & 0 & 0 & 0 \\
\hline Bacteria & Proteobacteria & Alphaproteobacteria & Rhodobacterales & Rhodobacteraceae & Rhodobacter & 0 & 0,028206093 & 0,015505078 & 0,1280662 & 0 \\
\hline Bacteria & Proteobacteria & Alphaproteobacteria & Rhodobacterales & Rhodobacteraceae & Ruegeria & 0 & 0,037608123 & 0 & 0 & 0 \\
\hline Bacteria & Proteobacteria & Alphaproteobacteria & Rhodobacterales & Rhodobacteraceae & Sulfitobacter & 0,01229861 & 0,084618278 & 0 & 0,019702492 & 0 \\
\hline Bacteria & Proteobacteria & Alphaproteobacteria & Rhodospirillales & Rhodospirillaceae & Uncl. Rhodospirillaceae & 0 & 0,075216247 & 0 & 0 & 0 \\
\hline Bacteria & Proteobacteria & Alphaproteobacteria & Rhodospirillales & Rhodospirillaceae & Skermanella & 0 & 0,009402031 & 0 & 0 & 0 \\
\hline Bacteria & Proteobacteria & Alphaproteobacteria & Rickettsiales & Uncl. Rickettsiales & Uncl. Rickettsiales & 0,024597221 & 0 & 0 & 0 & 0 \\
\hline Bacteria & Proteobacteria & Alphaproteobacteria & Sphingomonadales & Erythrobacteraceae & Other & 0,01229861 & 0,018804062 & 0 & 0 & 0 \\
\hline Bacteria & Proteobacteria & Alphaproteobacteria & Sphingomonadales & Erythrobacteraceae & Uncl. Erythrobacteraceae & 0 & 0,028206093 & 0 & 0 & 0 \\
\hline Bacteria & Proteobacteria & Alphaproteobacteria & Sphingomonadales & Sphingomonadaceae & Uncl. Sphingomonadaceae & 0 & 0,065814216 & 0 & 0 & 0 \\
\hline
\end{tabular}




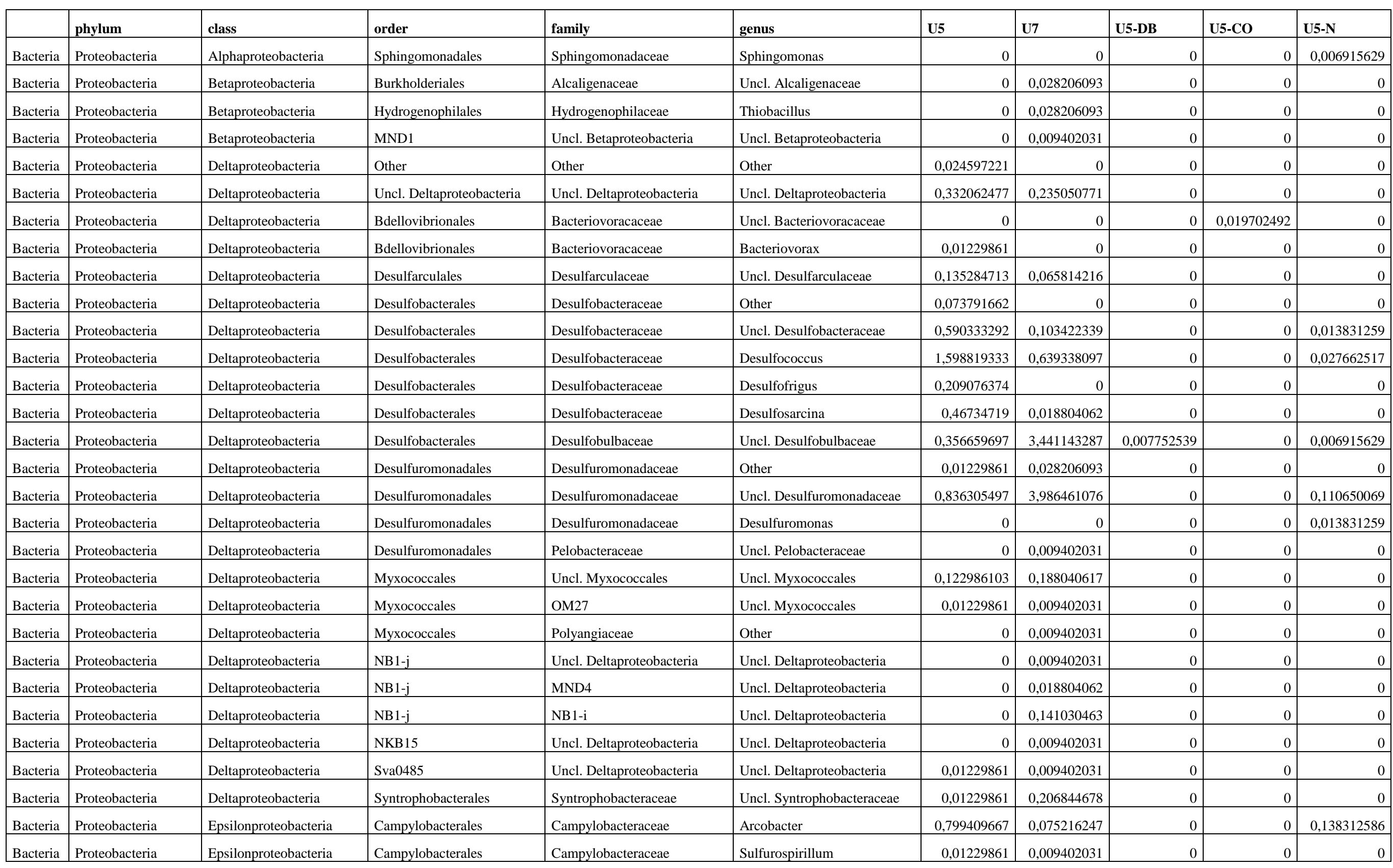




\begin{tabular}{|c|c|c|c|c|c|c|c|c|c|c|}
\hline & phylum & class & order & family & genus & U5 & U7 & U5-DB & U5-CO & U5-N \\
\hline Bacteria & Proteobacteria & Epsilonproteobacteria & Campylobacterales & Helicobacteraceae & Uncl. Helicobacteraceae & 8,338457754 & 2,02143663 & 0,015505078 & 0,019702492 & 1,341632089 \\
\hline Bacteria & Proteobacteria & Epsilonproteobacteria & Campylobacterales & Helicobacteraceae & Sulfurimonas & 0 & 0,018804062 & 0,085277929 & 0,167471185 & 0,242047026 \\
\hline Bacteria & Proteobacteria & Gammaproteobacteria & Uncl. Gammaproteobacteria & Uncl. Gammaproteobacteria & Uncl. Gammaproteobacteria & 0,098388882 & 0,11282437 & 0,007752539 & 0 & 0,006915629 \\
\hline Bacteria & Proteobacteria & Gammaproteobacteria & Aeromonadales & Aeromonadaceae & Other & 0 & 0,065814216 & 0 & 0 & 0 \\
\hline Bacteria & Proteobacteria & Gammaproteobacteria & Aeromonadales & Aeromonadaceae & Uncl. Gammaproteobacteria & 0,01229861 & 0,037608123 & 0,015505078 & 0 & 0 \\
\hline Bacteria & Proteobacteria & Gammaproteobacteria & Aeromonadales & Aeromonadaceae & Oceanimonas & 0,01229861 & 0,235050771 & 0 & 0 & 0 \\
\hline Bacteria & Proteobacteria & Gammaproteobacteria & Aeromonadales & Aeromonadaceae & Zobellella & 0 & 0,009402031 & 0 & 0 & 0 \\
\hline Bacteria & Proteobacteria & Gammaproteobacteria & Alteromonadales & Other & Other & 0,528840241 & 0 & 0,271338863 & 0,453157324 & 0,193637621 \\
\hline Bacteria & Proteobacteria & Gammaproteobacteria & Alteromonadales & Uncl. Alteromonadales & Uncl. Alteromonadales & 0,036895831 & 0,028206093 & 0 & 0,009851246 & 0,006915629 \\
\hline Bacteria & Proteobacteria & Gammaproteobacteria & Alteromonadales & Alteromonadaceae & Other & 0,01229861 & 0 & 0,007752539 & 0,059107477 & 0 \\
\hline Bacteria & Proteobacteria & Gammaproteobacteria & Alteromonadales & Alteromonadaceae & Marinobacter & 0 & 0 & 8,628575859 & 42,78396217 & 6,749654219 \\
\hline Bacteria & Proteobacteria & Gammaproteobacteria & Alteromonadales & Alteromonadaceae & Microbulbifer & 0 & 0 & 0,031010156 & 0 & 0 \\
\hline Bacteria & Proteobacteria & Gammaproteobacteria & Alteromonadales & Colwelliaceae & Uncl. Colwelliaceae & 0,676423564 & 0,094020308 & 0 & 0 & 0 \\
\hline Bacteria & Proteobacteria & Gammaproteobacteria & Alteromonadales & Ferrimonadaceae & Ferrimonas & 0 & 0 & 0 & 0 & 0,006915629 \\
\hline Bacteria & Proteobacteria & Gammaproteobacteria & Alteromonadales & HTCC 2188 & HTCC & 0 & 0,037608123 & 0 & 0 & 0 \\
\hline Bacteria & Proteobacteria & Gammaproteobacteria & Alteromonadales & Idiomarinaceae & Other & 0 & 0 & 0,023257617 & 0,118214954 & 0 \\
\hline Bacteria & Proteobacteria & Gammaproteobacteria & Alteromonadales & Idiomarinaceae & Idiomarina & 0 & 0 & 0,038762695 & 0 & 0 \\
\hline Bacteria & Proteobacteria & Gammaproteobacteria & Alteromonadales & Idiomarinaceae & Pseudidiomarina & 0 & 0 & 0,038762695 & 0 & 0 \\
\hline Bacteria & Proteobacteria & Gammaproteobacteria & Alteromonadales & OM60 & Uncl. Alteromonadales & 4,673471898 & 0,66754419 & 0 & 0 & 0,013831259 \\
\hline Bacteria & Proteobacteria & Gammaproteobacteria & Alteromonadales & OM60 & Congregibacter & 0 & 0,009402031 & 0 & 0 & 0 \\
\hline Bacteria & Proteobacteria & Gammaproteobacteria & Alteromonadales & Psychromonadaceae & Psychromonas & 4,169228877 & 3,638585935 & 0 & 0 & 0 \\
\hline Bacteria & Proteobacteria & Gammaproteobacteria & Alteromonadales & Shewanellaceae & Shewanella & 2,631902595 & 0,949605115 & 0,116288084 & 0,009851246 & 0,027662517 \\
\hline Bacteria & Proteobacteria & Gammaproteobacteria & Chromatiales & Other & Other & 0,024597221 & 0 & 0 & 0 & 0 \\
\hline Bacteria & Proteobacteria & Gammaproteobacteria & Chromatiales & Uncl. Chromatiales & Uncl. Chromatiales & 6,395277334 & 0,611132005 & 0 & 0 & 0,096818811 \\
\hline Bacteria & Proteobacteria & Gammaproteobacteria & Chromatiales & Chromatiaceae & Other & 0,036895831 & 0 & 0 & 0 & 0 \\
\hline Bacteria & Proteobacteria & Gammaproteobacteria & Chromatiales & Ectothiorhodospiraceae & Uncl. Ectothiorhodospiraceae & 0,024597221 & 0 & 0 & 0 & 0 \\
\hline Bacteria & Proteobacteria & Gammaproteobacteria & HTCC2188 & HTCC2089 & Uncl. Gammaproteobacteria & 0,024597221 & 0,009402031 & 0 & 0 & 0 \\
\hline
\end{tabular}




\begin{tabular}{|c|c|c|c|c|c|c|c|c|c|c|}
\hline & phylum & class & order & family & genus & U5 & U7 & U5-DB & U5-CO & U5-N \\
\hline Bacteria & Proteobacteria & Gammaproteobacteria & Legionellales & Uncl. Legionellales & Uncl. Legionellales & 0 & 0,047010154 & 0 & 0 & 0 \\
\hline Bacteria & Proteobacteria & Gammaproteobacteria & Legionellales & Coxiellaceae & Uncl. Coxiellaceae & 0,01229861 & 0,009402031 & 0 & 0 & 0 \\
\hline Bacteria & Proteobacteria & Gammaproteobacteria & Oceanospirillales & Uncl. Oceanospirillales & Uncl. Oceanospirillales & 0 & 0 & 0,007752539 & 0 & 0 \\
\hline Bacteria & Proteobacteria & Gammaproteobacteria & Oceanospirillales & Alcanivoracaceae & Alcanivorax & 0 & 0 & 58,2680828 & 30,38124323 & 0 \\
\hline Bacteria & Proteobacteria & Gammaproteobacteria & Oceanospirillales & Halomonadaceae & Other & 0 & 0 & 0 & 0,019702492 & 1,639004149 \\
\hline Bacteria & Proteobacteria & Gammaproteobacteria & Oceanospirillales & Halomonadaceae & Candidatus Portiera & 0,01229861 & 0 & 0 & 0,039404985 & 0 \\
\hline Bacteria & Proteobacteria & Gammaproteobacteria & Oceanospirillales & Halomonadaceae & Cobetia & 0 & 0 & 0 & 0,019702492 & 0 \\
\hline Bacteria & Proteobacteria & Gammaproteobacteria & Oceanospirillales & Halomonadaceae & Halomonas & 0 & 0 & 0,015505078 & 0,098512462 & 15,5186722 \\
\hline Bacteria & Proteobacteria & Gammaproteobacteria & Oceanospirillales & Oceanospirillaceae & Other & 0 & 0 & 0,124040623 & 0,009851246 & 0 \\
\hline Bacteria & Proteobacteria & Gammaproteobacteria & Oceanospirillales & Oceanospirillaceae & Uncl. Oceanospirillaceae & 0 & 0 & 0,093030467 & 0,049256231 & 0,013831259 \\
\hline Bacteria & Proteobacteria & Gammaproteobacteria & Oceanospirillales & Oceanospirillaceae & Marinobacterium & 0 & 0 & 11,35746957 & 17,50566447 & 0 \\
\hline Bacteria & Proteobacteria & Gammaproteobacteria & Oceanospirillales & Oceanospirillaceae & Nitrincola & 0 & 0 & 5,256221413 & 0,679735987 & 1,092669433 \\
\hline Bacteria & Proteobacteria & Gammaproteobacteria & Oceanospirillales & Oceanospirillaceae & Oleispira & 0 & 1,090635577 & 0 & 0 & 0 \\
\hline Bacteria & Proteobacteria & Gammaproteobacteria & Pseudomonadales & Other & Other & 0 & 0,159834524 & 0 & 0 & 0 \\
\hline Bacteria & Proteobacteria & Gammaproteobacteria & Pseudomonadales & Moraxellaceae & Uncl. Moraxellaceae & 0,024597221 & 0,902594961 & 0 & 0 & 0 \\
\hline Bacteria & Proteobacteria & Gammaproteobacteria & Pseudomonadales & Moraxellaceae & Acinetobacter & 0 & 0 & 0 & 0 & 0,027662517 \\
\hline Bacteria & Proteobacteria & Gammaproteobacteria & Pseudomonadales & Moraxellaceae & Psychrobacter & 0 & 0,009402031 & 0 & 0 & 0 \\
\hline Bacteria & Proteobacteria & Gammaproteobacteria & Pseudomonadales & Pseudomonadaceae & Other & 0 & 0 & 0,759748818 & 0 & 0 \\
\hline Bacteria & Proteobacteria & Gammaproteobacteria & Pseudomonadales & Pseudomonadaceae & Uncl. Pseudomonadaceae & 0 & 0 & 0,007752539 & 0 & 0 \\
\hline Bacteria & Proteobacteria & Gammaproteobacteria & Pseudomonadales & Pseudomonadaceae & Pseudomonas & 0 & 0,084618278 & 8,938677417 & 0,039404985 & 0,691562932 \\
\hline Bacteria & Proteobacteria & Gammaproteobacteria & Thiohalorhabdales & Uncl. Thiohalorhabdales & Uncl. Thiohalorhabdales & 0,528840241 & 0,206844678 & 0 & 0 & 0,006915629 \\
\hline Bacteria & Proteobacteria & Gammaproteobacteria & Thiotrichales & Uncl. Thiotrichales & Uncl. Thiotrichales & 0,356659697 & 0,009402031 & 0 & 0 & 0,013831259 \\
\hline Bacteria & Proteobacteria & Gammaproteobacteria & Thiotrichales & Piscirickettsiaceae & Uncl. Piscirickettsiaceae & 1,89398598 & 3,666792027 & 0 & 0 & 0 \\
\hline Bacteria & Proteobacteria & Gammaproteobacteria & Thiotrichales & Piscirickettsiaceae & Methylophaga & 0 & 0 & 0,837274207 & 0,019702492 & 3,665283541 \\
\hline Bacteria & Proteobacteria & Gammaproteobacteria & Thiotrichales & Thiotrichaceae & Uncl. Thiotrichaceae & 3,185340057 & 0,11282437 & 0 & 0 & 0 \\
\hline Bacteria & Proteobacteria & Gammaproteobacteria & Vibrionales & Other & Other & 0,024597221 & 0 & 0 & 0 & 0 \\
\hline Bacteria & Proteobacteria & Gammaproteobacteria & Vibrionales & Pseudoalteromonadaceae & Pseudoalteromonas & 2,41052761 & 4,992478375 & 0,007752539 & 0 & 0 \\
\hline
\end{tabular}




\begin{tabular}{|c|c|c|c|c|c|c|c|c|c|c|}
\hline & phylum & class & order & family & genus & U5 & U7 & U5-DB & U5-CO & U5-N \\
\hline Bacteria & Proteobacteria & Gammaproteobacteria & Vibrionales & Vibrionaceae & Other & 0,147583323 & 0,009402031 & 0 & 0 & 0 \\
\hline Bacteria & Proteobacteria & Gammaproteobacteria & Vibrionales & Vibrionaceae & Uncl. Vibrionaceae & 2,570409544 & 0,047010154 & 0 & 0 & 0 \\
\hline Bacteria & Proteobacteria & Gammaproteobacteria & Vibrionales & Vibrionaceae & Vibrio & 0,528840241 & 0 & 0 & 0,531967294 & 0 \\
\hline Bacteria & Proteobacteria & Gammaproteobacteria & Xanthomonadales & Sinobacteraceae & Uncl. Sinobacteraceae & 0 & 0,056412185 & 0 & 0 & 0 \\
\hline Bacteria & Proteobacteria & Gammaproteobacteria & Xanthomonadales & Sinobacteraceae & Steroidobacter & 0 & 0,009402031 & 0 & 0 & 0 \\
\hline Bacteria & Proteobacteria & Gammaproteobacteria & Xanthomonadales & Xanthomonadaceae & Lysobacter & 0 & 0,009402031 & 0 & 0 & 0 \\
\hline Bacteria & Proteobacteria & Gammaproteobacteria & [Marinicellales] & [Marinicellaceae] & Uncl. Gammaproteobacteria & 5,460582954 & 3,525761565 & 0 & 0 & 0,041493776 \\
\hline Bacteria & Proteobacteria & TA18 & CV90 & Uncl. Proteobacteria & Uncl. Proteobacteria & 0,01229861 & 0,028206093 & 0 & 0 & 0 \\
\hline Bacteria & Proteobacteria & Zetaproteobacteria & Mariprofundales & Mariprofundaceae & Mariprofundus & 0 & 0 & 0 & 0 & 0,013831259 \\
\hline Bacteria & SAR406 & $\mathrm{AB} 16$ & Uncl. Bacteria & Uncl. Bacteria & Uncl. Bacteria & 0 & 0 & 0 & 0 & 0,006915629 \\
\hline Bacteria & SAR406 & $\mathrm{AB} 16$ & Arctic96B-7 & A714017 & so4B24 & 0,01229861 & 0,056412185 & 0 & 0 & 0 \\
\hline Bacteria & SBR1093 & VHS-B5-50 & Uncl. Bacteria & Uncl. Bacteria & Uncl. Bacteria & 0 & 0,047010154 & 0 & 0 & 0 \\
\hline Bacteria & Spirochaetes & Spirochaetes & Spirochaetales & Spirochaetaceae & Spirochaeta & 0,233673595 & 0,103422339 & 0 & 0 & 0 \\
\hline Bacteria & Spirochaetes & [Brachyspirae] & [Brachyspirales] & $\mathrm{A} 0-023$ & Uncl. A0-023 & 0 & 0,009402031 & 0 & 0 & 0 \\
\hline Bacteria & Spirochaetes & [Leptospirae] & [Leptospirales] & Sediment-4 & SJA- 88 & 0 & 0,018804062 & 0 & 0 & 0 \\
\hline Bacteria & TM6 & SBRH58 & Uncl. Bacteria & Uncl. Bacteria & Uncl. Bacteria & 0 & 0,009402031 & 0 & 0 & 0 \\
\hline Bacteria & TM6 & SJA-4 & Uncl. Bacteria & Uncl. Bacteria & Uncl. Bacteria & 0,01229861 & 0,009402031 & 0 & 0 & 0 \\
\hline Bacteria & TPD-58 & Uncl. Bacteria & Uncl. Bacteria & Uncl. Bacteria & Uncl. Bacteria & 0 & 0,028206093 & 0 & 0 & 0 \\
\hline Bacteria & Tenericutes & Mollicutes & Uncl. Mollicutes & Uncl. Mollicutes & Uncl. Mollicutes & 0 & 0,056412185 & 0 & 0 & 0,034578147 \\
\hline Bacteria & Tenericutes & Mollicutes & Acholeplasmatales & Acholeplasmataceae & Uncl. Acholeplasmataceae & 0 & 0 & 0 & 0 & 0,006915629 \\
\hline Bacteria & Verrucomicrobia & Opitutae & Uncl. Mollicutes & Uncl. Mollicutes & Uncl. Mollicutes & 0,01229861 & 0,018804062 & 0 & 0 & 0 \\
\hline Bacteria & Verrucomicrobia & Opitutae & Opitutales & Opitutaceae & Opitutus & 0 & 0,018804062 & 0 & 0 & 0 \\
\hline Bacteria & Verrucomicrobia & Opitutae & [Pelagicoccales] & [Pelagicoccaceae] & Pelagicoccus & 0 & 0,009402031 & 0 & 0 & 0 \\
\hline Bacteria & Verrucomicrobia & Verruco-5 & Uncl. Verrucomicrobia & Uncl. Verrucomicrobia & Uncl. Verrucomicrobia & 0 & 0,009402031 & 0 & 0 & 0 \\
\hline Bacteria & Verrucomicrobia & Verruco-5 & LD1-PB3 & LD1-PA34 & Uncl. LD1-PA34 & 0 & 0,009402031 & 0 & 0 & 0 \\
\hline Bacteria & Verrucomicrobia & Verruco-5 & R76-B128 & Uncl. Verrucomicrobia & Uncl. Verrucomicrobia & 0,110687492 & 0,141030463 & 0 & 0 & 0 \\
\hline Bacteria & Verrucomicrobia & Verrucomicrobiae & Verrucomicrobiales & Verrucomicrobiaceae & Uncl. Verrucomicrobiaceae & 0,024597221 & 0,009402031 & 0 & 0 & 0 \\
\hline
\end{tabular}




\begin{tabular}{|c|c|c|c|c|c|c|c|c|c|c|}
\hline & phylum & class & order & family & genus & U5 & U7 & U5-DB & U5-CO & U5-N \\
\hline Bacteria & Verrucomicrobia & Verrucomicrobiae & Verrucomicrobiales & Verrucomicrobiaceae & Haloferula & 0,01229861 & 0 & 0 & 0 & 0 \\
\hline Bacteria & Verrucomicrobia & Verrucomicrobiae & Verrucomicrobiales & Verrucomicrobiaceae & Luteolibacter & 0 & 0 & 0 & 0 & 0,006915629 \\
\hline Bacteria & Verrucomicrobia & [Pedosphaerae] & [Pedosphaerales] & Uncl. Verrucomicrobia & Uncl. Verrucomicrobia & 0 & 0,018804062 & 0 & 0 & 0 \\
\hline Bacteria & Verrucomicrobia & [Spartobacteria] & [Chthoniobacterales] & [Chthoniobacteraceae] & DA101 & 0 & 0,018804062 & 0 & 0 & 0 \\
\hline Bacteria & WS2 & Kazan-3B-09 & Uncl. WS2 & Uncl. WS2 & Uncl. WS2 & 0,036895831 & 0,018804062 & 0 & 0 & 0 \\
\hline Bacteria & WS2 & SHA-109 & Uncl. WS2 & Uncl. WS2 & Uncl. WS2 & 0,024597221 & 0,028206093 & 0 & 0 & 0 \\
\hline Bacteria & WS3 & PRR-12 & Uncl. WS3 & Uncl. WS3 & Uncl. WS3 & 0,393555528 & 0,028206093 & 0 & 0 & 0 \\
\hline Bacteria & WS3 & PRR-12 & GN03 & Uncl. WS3 & Uncl. WS3 & 0,073791662 & 0,056412185 & 0 & 0 & 0 \\
\hline Bacteria & WS3 & PRR-12 & GN03 & KSB4 & Uncl. WS3 & 1,217562415 & 0,488905604 & 0 & 0 & 0 \\
\hline Bacteria & WS3 & PRR-12 & LD1-PA13 & Uncl. WS3 & Uncl. WS3 & 0,049194441 & 0 & 0 & 0 & 0 \\
\hline Bacteria & WS3 & PRR-12 & SSS58A & Uncl. WS3 & Uncl. WS3 & 0,344361087 & 0 & 0 & 0 & 0,006915629 \\
\hline Bacteria & WS3 & PRR-12 & Sediment-1 & Uncl. WS3 & Uncl. WS3 & 0,098388882 & 0,150432493 & 0 & 0 & 0 \\
\hline Bacteria & WS3 & PRR-12 & Sediment-1 & MSB-4E2 & Uncl. WS3 & 0,147583323 & 0,018804062 & 0 & 0 & 0 \\
\hline Bacteria & WS3 & PRR-12 & Sediment-1 & PRR-10 & Uncl. WS3 & 0 & 0,028206093 & 0 & 0 & 0 \\
\hline Bacteria & WWE1 & [Cloacamonae] & [Cloacamonales] & MSBL8 & Uncl. WWE1 & 0 & 0,009402031 & 0 & 0 & 0 \\
\hline Bacteria & [Caldithrix] & KSB1 & Uncl. Bacteria & Uncl. Bacteria & Uncl. Bacteria & 0 & 0,009402031 & 0 & 0 & 0 \\
\hline Bacteria & [Caldithrix] & KSB1 & GW-22 & Uncl. Bacteria & Uncl. Bacteria & 0,036895831 & 0 & 0 & 0 & 0 \\
\hline
\end{tabular}




\section{Table S2}

alkB DGGE bands identification. Bands excised from DGGE gels are indicated on Figure 2d.

\begin{tabular}{|c|c|c|c|c|c|c|c|c|c|c|c|}
\hline BAND & SAMPLE & CLOSEST RELATIVE & GENE & $\operatorname{ACCN}$ & LENGHT & $\%$ & CLOSEST DESCRIBED SPECIE & GENE & $\operatorname{ACCN}$ & LENGHT & $\%$ \\
\hline 1 & $\mathrm{U} 7-\mathrm{CO}$ & Uncultured bacterium & alkane hydroxylase B (alkB) gene & JQ279687 & $369 / 453$ & 81 & Marinobacter adhaerens & complete genome & CP001978 & $364 / 449$ & 81 \\
\hline 2 & $\mathrm{U} 7-\mathrm{CO}$ & Uncultured bacterium & alkane hydroxylase B (alkB) gene & JQ279687 & $364 / 443$ & 82 & Marinobacter adhaerens & complete genome & CP001978 & $359 / 441$ & 81 \\
\hline 3 & $\mathrm{U} 7-\mathrm{CO}$ & Uncultured bacterium & alkane hydroxylase (alkB) gene & JN986869 & $364 / 434$ & 84 & Marinobacter adhaerens & complete genome & CР001978 & $357 / 428$ & 83 \\
\hline 4 & $\mathrm{U} 7-\mathrm{CO}$ & Uncultured bacterium & alkane hydroxylase (alkB) gene & JN986869 & $384 / 452$ & 85 & Marinobacter adhaerens & complete genome & CP001978 & $375 / 451$ & 83 \\
\hline 5 & U7-DB & Uncultured bacterium & alkane monooxygenase (alkB) gene & GQ184418 & $328 / 431$ & 76 & Simiduia agarivorans & complete genome & СР003746 & $134 / 173$ & 77 \\
\hline 6 & U7-DS & Uncultured bacterium & alkane monooxygenase (alkB) gene & JX276499 & $316 / 343$ & 92 & Marinobacter hydrocarbonoclasticus & alkane hydroxylase (alkB) gene & EU853368 & $281 / 344$ & 82 \\
\hline 7 & $\mathrm{U} 7-\mathrm{CO}$ & Uncultured bacterium & alkane monooxygenase (alkB) gene & JQ279687 & $368 / 449$ & 82 & Marinobacter adhaerens & complete genome & $\mathrm{CP} 001978$ & $364 / 449$ & 81 \\
\hline 8 & U7-DB & Uncultured bacterium & alkane monooxygenase (alkB) gene & JQ279687 & $366 / 449$ & 82 & Marinobacter adhaerens & complete genome & CP001978 & $355 / 437$ & 81 \\
\hline 9 & $\mathrm{U} 7-\mathrm{CO}$ & Uncultured bacterium & putative alkane monooxygenase (alkB) gene & JQ437623 & $235 / 281$ & 84 & Alcanivorax borkumensis & alkane hydroxylase (alkB) gene & EU853322 & $97 / 123$ & 79 \\
\hline 10 & $\mathrm{U} 7-\mathrm{CO}$ & Uncultured bacterium & alkane hydroxylase B (alkB) gene & JQ279685 & $381 / 451$ & 84 & Marinobacter adhaerens & complete genome & CP001978 & $376 / 449$ & 84 \\
\hline 11 & U7-DS & Uncultured bacterium & alkane hydroxylase B (alkB) gene & JQ279687 & $372 / 455$ & 82 & Marinobacter adhaerens & complete genome & CP001978 & $363 / 449$ & 81 \\
\hline 12 & U7-DS & Uncultured bacterium & alkane hydroxylase B (alkB) gene & JQ279687 & $383 / 470$ & 81 & Marinobacter adhaerens & complete genome & CP001978 & $379 / 466$ & 82 \\
\hline 13 & U5-CO & Uncultured bacterium & alkane hydroxylase (alkB) gene & JN986861 & $295 / 344$ & 86 & Alcanivorax hongdengensis & alkane hydroxylase (alkB) gene & EU438898 & $186 / 230$ & 81 \\
\hline 14 & $\mathrm{U} 5-\mathrm{CO}$ & Uncultured bacterium & alkane hydroxylase (alkB) gene & JN986869 & $358 / 381$ & 94 & Marinobacter adhaerens & complete genome & CP001978 & $323 / 377$ & 86 \\
\hline 15 & U5-CO & Uncultured bacterium & alkane hydroxylase (alkB) gene & JQ279685 & $352 / 374$ & 94 & Marinobacter adhaerens & complete genome & CP001978 & $319 / 375$ & 85 \\
\hline 16 & U5-DB & Marinobacter adhaerens & complete genome & СР001978 & $250 / 316$ & 79 & Marinobacter adhaerens & complete genome & CP001978 & $250 / 316$ & 79 \\
\hline 17 & U5-CO & Uncultured bacterium & alkane hydroxylase (alkB) gene & JQ279685 & $402 / 418$ & 96 & Marinobacter adhaerens & complete genome & CP001978 & $362 / 416$ & 87 \\
\hline 18 & U5-DS & Uncultured bacterium & alkane hydroxylase (alkB) gene & JQ279685 & $405 / 418$ & 97 & Marinobacter adhaerens & complete genome & CP001978 & $364 / 416$ & 88 \\
\hline 19 & U5-DB & Uncultured bacterium & alkane hydroxylase (alkB) gene & JN986869 & $417 / 434$ & 96 & Marinobacter adhaerens & complete genome & CP001978 & $372 / 428$ & 87 \\
\hline 20 & U5-DS & Uncultured bacterium & alkane hydroxylase (alkB) gene & JQ279685 & $403 / 418$ & 96 & Marinobacter adhaerens & complete genome & CP001978 & $360 / 416$ & 87 \\
\hline 21 & U5-DB & Uncultured bacterium & alkane hydroxylase (alkB) gene & JQ279685 & $408 / 427$ & 96 & Marinobacter adhaerens & complete genome & CP001978 & $366 / 427$ & 86 \\
\hline 22 & $\mathrm{U} 5-\mathrm{CO}$ & Uncultured bacterium & alkane hydroxylase (alkB) gene & JQ279685 & $294 / 333$ & 88 & Marinobacter hydrocarbonoclasticus & alkane hydroxylase (alkB) gene & EU853368 & $281 / 335$ & 84 \\
\hline 23 & $\mathrm{U} 5-\mathrm{CO}$ & Uncultured bacterium & alkane hydroxylase (alkB) gene & JN986869 & $409 / 434$ & 94 & Marinobacter adhaerens & complete genome & CP001978 & $367 / 428$ & 86 \\
\hline 24 & $\mathrm{U} 5-\mathrm{CO}$ & Uncultured bacterium & alkane hydroxylase (alkB) gene & JQ279685 & $408 / 431$ & 95 & Marinobacter adhaerens & complete genome & CP001978 & $368 / 429$ & 86 \\
\hline 25 & U5-DB & Uncultured bacterium & alkane hydroxylase (alkB) gene & JQ279687 & $342 / 424$ & 81 & Marinobacter hydrocarbonoclasticus & alkane hydroxylase (alkB) gene & EU853368 & $331 / 415$ & 80 \\
\hline 26 & U5-DB & Marinobacter sp. EPR21 & hydroxylase (alkB) gene & KC610508 & $370 / 403$ & 92 & Alcanivorax hongdengensis & alkane hydroxylase (alkB) gene & EU438898 & $243 / 295$ & 82 \\
\hline 27 & U5-DS & Uncultured bacterium & alkane hydroxylase (alkB) gene & JX276502 & $383 / 468$ & 82 & Marinobacter adhaerens & complete genome & CP001978 & $381 / 476$ & 80 \\
\hline 28 & U5-DB & Uncultured bacterium & alkane hydroxylase (alkB) gene & JQ279687 & $377 / 455$ & 83 & Marinobacter adhaerens & complete genome & $\mathrm{CP} 001978$ & $365 / 449$ & 81 \\
\hline 29 & U5-DB & Uncultured bacterium & alkane hydroxylase B (alkB) gene & JQ279687 & $390 / 472$ & 83 & Marinobacter adhaerens & complete genome & CP001978 & $379 / 466$ & 81 \\
\hline 30 & $\mathrm{U} 5-\mathrm{CO}$ & Uncultured bacterium & alkane hydroxylase B (alkB) gene & JQ279687 & $385 / 472$ & 81 & Marinobacter adhaerens & complete genome & CP001978 & $377 / 466$ & 81 \\
\hline 31 & U5-CO & Uncultured bacterium & alkane hydroxylase B (alkB) gene & JN986869 & $393 / 435$ & 90 & Marinobacter adhaerens & complete genome & CP001978 & $360 / 425$ & 85 \\
\hline 32 & U5-CO & Uncultured bacterium & alkane hydroxylase B (alkB) gene & JQ279685 & $381 / 419$ & 91 & Marinobacter adhaerens & complete genome & CP001978 & $349 / 414$ & 84 \\
\hline
\end{tabular}




\begin{tabular}{|c|c|c|c|c|c|c|c|c|c|c|c|}
\hline BAND & SAMPLE & CLOSEST RELATIVE & GENE & $\operatorname{ACCN}$ & LENGHT & $\%$ & CLOSEST DESCRIBED SPECIE & GENE & $\operatorname{ACCN}$ & LENGHT & $\%$ \\
\hline 33 & U5-CO & Uncultured bacterium & alkane hydroxylase B (alkB) gene & JN986869 & $357 / 381$ & 94 & Marinobacter adhaerens & complete genome & CP001978 & $321 / 377$ & 85 \\
\hline 34 & U5-CO & Uncultured bacterium & alkane hydroxylase B (alkB) gene & JQ279685 & $364 / 389$ & 94 & Marinobacter adhaerens & complete genome & CP001978 & $333 / 392$ & 85 \\
\hline 35 & $\mathrm{U} 5-\mathrm{CO}$ & Uncultured bacterium & alkane hydroxylase B (alkB) gene & JQ279685 & $358 / 382$ & 94 & Marinobacter adhaerens & complete genome & CP001978 & $321 / 377$ & 85 \\
\hline 36 & U5-DS & Uncultured bacterium & alkane hydroxylase B (alkB) gene & JQ279685 & $461 / 484$ & 95 & Marinobacter adhaerens & complete genome & CP001978 & $420 / 482$ & 87 \\
\hline 37 & U5-DS & Uncultured bacterium & alkane hydroxylase B (alkB) gene & JN986869 & $417 / 434$ & 96 & Marinobacter adhaerens & complete genome & CP001978 & $368 / 428$ & 86 \\
\hline 38 & U5-DS & Uncultured bacterium & alkane hydroxylase B (alkB) gene & JN986869 & $417 / 434$ & 96 & Marinobacter adhaerens & complete genome & CP001978 & $368 / 428$ & 86 \\
\hline 39 & U5-DS & Uncultured bacterium & alkane hydroxylase B (alkB) gene & JQ279685 & $345 / 367$ & 94 & Marinobacter adhaerens & complete genome & CP001978 & $315 / 367$ & 86 \\
\hline 40 & U5-DS & Uncultured bacterium & alkane hydroxylase B (alkB) gene & JQ279685 & $419 / 436$ & 96 & Marinobacter adhaerens & complete genome & CP001978 & $368 / 428$ & 86 \\
\hline
\end{tabular}

